\title{
O EFEITO DE APOSENTADORIAS, PENSÕES E PROGRAMAS SOCIAIS NA FREQUÊNCIA ESCOLAR E OFERTA DE TRABALHO DOS JOVENS BRASILEIROS
}

\author{
Luciana de Oliveira Rodrigues * \\ Edward Martins Costa ${ }^{\dagger}$ \\ Francisca Zilania Mariano ${ }^{\ddagger}$ \\ João Paulo Martins Guedes $\S$
}

\begin{abstract}
Resumo
A pesquisa analisou o impacto de aposentadorias/pensões e programas sociais sobre a frequência escolar e oferta de trabalho dos jovens de 15 a 21 anos de idade. Dos resultados encontrados, verificou-se que em domicílios em que residem aposentados e/ou pensionistas há uma redução na oferta de trabalho e aumento da frequência escolar dos jovens nas áreas urbanas. Concluiu-se que o impacto de programas sociais, tanto na zona urbana, como no meio rural, aumenta as chances de os jovens estudarem e trabalharem, sendo que o efeito médio sobre aqueles jovens "nem-nem" é menor.
\end{abstract}

Palavras-chave: jovens; aposentadorias; pensões; programas sociais; Propensity Score Matching.

\begin{abstract}
This research analyses the i mpact of pensions and social programs school attendance and supply in the labor market of young people aged 15 to 21 years. Itwas verified in households where retirees and/or pensioners 1 ive a reduction in the 1 abor supply and an i ncrease in school attendance of young people in urban areas. It was concluded that the i mpact of social programs, both in urban and rural areas, i ncreases the chances of young people studying and working, and the average effect on those young people who are neither working nor studying (NEET) is s maller.
\end{abstract}

Keywords: young; retirements; pension; social programs; Propensity Score Matching.

JEL classification: J 13, J 22, J 26.

DOI: http://dx.doi.org/10.11606/1980-5330/ea131198

\footnotetext{
* Analista de Políticas Públicas do Instituto de Pesquisa e Estratégia Econômica do Estado do Ceará (IPECE). E-mail: lrodrigues_s@hotmail.com.

${ }^{\dagger}$ Professor do Mestrado Acadêmico em Economia Rural (MAER/UFC). E-mail: edwardcost@gmail.com.

‡ Professora dos Cursos de Economia e Finanças (UFC/SOBRAL). E-mail: zilania@ufc.br.

$\S$ Professor Adjunto do Departamento de Economia da Universidade Federal do Rio Grande do Norte (UFRN).E-mail: jpmartins@ufrnet.br.
} 


\section{Introdução}

A juventude ${ }^{1}$ é um período marcado por escolhas fundamentais que terão reflexo por toda a vida do indivíduo. Embora seja uma fase caracterizada por um conjunto de transformações, tanto em sentido físico, como social e econômico, é nesse período de transição, entre a infância e a vida adulta, que os indivíduos são obrigados a decidir sobre questões relacionadas a aspectos educacionais e escolhas profissionais.

Assim, muitas dessas escolhas estão sujeitas ao contexto socioeconômico ao qual pertencem. Dependendo da trajetória que decidirem seguir, essas escolhas serão responsáveis por fatores que ampliarão suas potencialidades ou limitarão seu desempenho, resultando em adultos mais ou menos vulneráveis (Camarano et al. 2004).

Os jovens, embora considerados a "geração do futuro", por apresentarem grandes potencialidades econômicas e produtivas, são também os mais vulneráveis às mudanças socioeconômicas. Nos centros urbanos, com a ampliação das oportunidades de acesso à educação formal, eles têm alcançado níveis de ensino cada vez mais elevados, o que possibilita melhores remunerações e aquisição de mais habilidades para as transformações tecnológicas do mercado de trabalho (Camarano et al. 2004). Por outro lado, em virtude da pouca experiência adquirida e da baixa qualificação, eles estão inseridos em posições mais precárias e com menos estabilidade, sendo os últimos a encontrar emprego e os primeiros a serem demitidos. Esse fato gera alta rotatividade e taxas de desemprego mais elevadas que as da população adulta Reis (2013).

No meio rural, as possibilidades do mercado de trabalho, a precarização da oferta de mão de obra e os baixos salários têm sido as principais razões da fuga dos jovens para os grandes centros urbanos. Esse fato tem sido visto como um grande problema social, na medida em que, não só contribui para o esvaziamento do campo e sobrecarga do mercado de trabalho na zona urbana, como também antecipa o envelhecimento relativo da população rural e limita o desempenho das atividades agrícolas (Ferreira \& Alves 2009).

Portanto, os jovens de famílias de baixa renda, no Brasil, independentemente do espaço geográfico a que fazem parte, estão expostos a inúmeros fatores que limitam sua trajetória escolar e os levam ao mercado de trabalho em idade precoce. Idade esta em que deveriam estar aumentando seu capital humano e adquirindo qualificações para, então, serem absorvidos pelo mercado de trabalho em posições menos precárias.

Outro fator, são os jovens brasileiros que, mesmo em idade escolar, nem estão na escola e nem fazem parte da População Economicamente Ativa (PEA) ${ }^{2}$,

\footnotetext{
${ }^{1}$ Segundo o IBGE e a Organização das Nações Unidas (ONU) a população jovem é composta por pessoas de 15 a 24 anos de idade. No entanto, este estudo considera como jovens as pessoas de 15 a 21 anos, assim como foi definido no trabalho Reis \& Camargo (2007) e Hoffmann (2010).

${ }^{2}$ Segundo a classificação adotada pelo IBGE, a População Economicamente Ativa - PEA - compreende o potencial de mão de obra com que pode contar o setor produtivo, isto é, a população ocupada e a população desocupada, ou seja, pessoas que estavam procurando emprego na semana de referência da pesquisa.
} 
conhecidos por "nem-nem". Segundo informações da Pesquisa Nacional por Amostra dos domicílios (PNAD), em 2014, cerca de 2,9 milhões de jovens de 15 a 21 anos faziam parte desse grupo, isto é, não frequentavam a escola e não estavam inseridos no mercado de trabalho, assim como não procuravam emprego, representando $12,6 \%$ da população nessa faixa etária.

Esse fenômeno pode representar implicações importantes em sentido social e econômico no país. Não frequentar a escola pode acarretar prejuízo ao desenvolvimento socioeconômico da nação, visto que a educação é apontada como um fator essencial no desempenho dos países (Camarano \& Kanso 2012). Além disso, não estar frequentando a escola e o mercado de trabalho torna os jovens vulneráveis socialmente, apresentando maior potencialidade em envolver-se com atividades criminosas e ilegais (Siqueira 2015).

Desse modo, as famílias assumem um papel importante nas decisões a serem tomadas pelos jovens. Diversos estudos que analisaram a alocação do tempo destes no mercado de trabalho, e estudos têm mostrado como a escolaridade do chefe do domicílio, o tamanho da família e o número de crianças podem ser decisivos em seu comportamento (Camarano \& Kanso 2012). A renda domiciliar também pode explicar, em parte, a decisão do jovem em inserir-se no mercado de trabalho ou investir nos estudos por mais tempo (Cabanas et al. 2014). Além disso, a presença de beneficiários de aposentadorias e pensões no domicílio pode ser um incentivo para o jovem permanecer na escola, tanto pelos custos diretos da educação, quanto pela redução do custo de oportunidade de estudar (Reis \& Camargo 2007).

Os programas sociais ou de transferências de renda também assumem um papel importante na formação social e econômica dos jovens de famílias pobres no Brasil. Além de representarem um importante complemento da renda familiar, o Programa Bolsa Família (PBF) e o Programa de Erradicação do Trabalho Infantil (PETI) possibilitam o rompimento do ciclo intergeracional da pobreza, por incentivar a permanência das crianças e adolescentes na escola.

Embora o objetivo principal do PBF não seja diretamente o combate ao trabalho infanto-juvenil, na medida em que se exige a frequência escolar, pode exercer um impacto positivo na acumulação de capital humano das crianças e dos jovens de famílias beneficiárias. Portanto, pressupõe-se que a ajuda financeira concebida pelo programa melhoraria a frequência escolar e reduziria a entrada precoce de crianças e adolescentes no mercado de trabalho, na medida em que reduz, sobretudo, os custos indiretos da educação para as famílias pobres (Araújo et al. 2010).

Nesse contexto, o presente estudo tem por objetivo investigar com mais detalhes como rendimentos oriundos de aposentadorias, pensões e programas sociais podem influenciar nas decisões da oferta de mão de obra e frequência escolar dos jovens nos domicílios dos beneficiários, por meio de transferência intradomiciliar. Para encontrar os efeitos dos rendimentos citados sobre as decisões dos jovens de 15 a 21 anos, foram utilizados diferentes métodos para solucionar o viés de seleção relacionado a variáveis observáveis e não observáveis, que podem afetar os resultados estimados. Portanto, são utilizadas as seguintes metodologias: Blackwell et al. (2009), Propensity Score Matching (PSM), Análise de sensibilidade e a metodologia desenvolvida por (Millimet 
\& Tchernis 2012), para corrigir o víeis surgido quando a hipótese de Independência Condicional (CIA) não é atendida, ou seja, variáveis não observáveis afetam os resultados estimados pelo Propensity Score Matching.

A contribuição deste estudo para a literatura é dada primeiramente por introduzir o efeito dos programas sociais sobre a alocação de tempo dos jovens entre trabalho e estudos. Além disso, as metodologias utilizadas são diferentes das demais pesquisas que estudam essa temática, pois busca obter impactos mais robustos sobre as decisões dos jovens.

Além desta introdução, a primeira parte deste trabalho está estruturado em mais cinco seções. Na segunda seção, foi feita uma breve revisão da literatura sobre o tema e na terceira foi apresentada a metodologia e os dados da pesquisa. Na quarta seção, foram analisados os principais resultados obtidos pelo modelo econométrico e, na quinta seção, foram expostas as principais considerações do estudo.

\section{Revisão da Literatura}

A atual Constituição Federal admite que os jovens iniciem legalmente suas atividades no mercado de trabalho a partir dos 16 anos de idade, exceto nos casos de trabalho noturno, perigosos e insalubres, nos quais a idade mínima aceita é 18 anos (artigo $7^{\circ}$, inciso XXXIII). Ela também admite que adolescentes trabalhem, no entanto, somente a partir dos 14 anos e na condição de aprendiz, que implica uma carga horária reduzida, em formação técnica profissionalizante e que não prejudique o desenvolvimento do adolescente e sua frequência à escola (Lei ${ }^{0}$ 8.069, de 13 de julho de 1990). Em termos gerais, no Artigo 227 da Constituição de 1998 é mencionado o dever da família, da sociedade e do Estado em assegurar a todas as crianças, adolescentes e jovens o direito à vida, à dignidade, à formação profissional e à educação.

No entanto, muitos estudos têm apontado que o trabalho entre crianças e adolescentes em idade precoce ainda é uma realidade no Brasil. Segundo Becker et al. (2014), em 2013, aproximadamente 12,3\% das crianças e adolescentes de 5 a 17 anos de idade estavam inseridos no mercado de trabalho. Grande parte deles eram meninos e residentes na zona rural. Os autores explicam que a cultura do trabalho precoce está relacionada à justificativa de incorporar as crianças na força de trabalho para afastá-las da marginalidade.

Outra questão é a situação financeira das famílias, sobretudo daquelas que residem na área rural e que muitas vezes necessitam da contribuição da renda ou força de trabalho das crianças e dos adolescentes para a sobrevivência da família e dos pequenos negócios. A falta de infraestrutura ou acesso às escolas também podem afastar crianças e adolescentes da vida escolar e contribuir para entrada precoce em atividades informais, seja do setor agrícola ou que exijam baixa qualificação (Becker et al. 2014).

Além de estarem inseridos em postos de menor qualificação e de baixos salários, esses indivíduos alocam o tempo que deveria ser destinado aos estudos 
para o trabalho. Consequentemente, deterioram suas oportunidades futuras de auferir rendas mais elevadas e perpetuam, assim, as suas condições de pobreza (Cacciamali et al. 2010).

As tomadas de decisões dos jovens ao entrarem no mercado de trabalho ou a frequência escolar são diretamente relacionadas ao contexto familiar em que esses estão inseridos. Na família, além de representarem uma importante fonte de renda no presente, também apresentam a capacidade de acumular capital humano e inserirem-se em melhores posições de trabalho no futuro. Tais escolhas, no entanto, possuem elevados custos de oportunidade para a família, principalmente para aquelas de baixa renda, sobretudo no Brasil, onde a baixa qualidade da educação e a baixa perspectiva de remuneração futura, por meio do investimento em educação, favorecem o ingresso no mercado de trabalho de muitas crianças, adolescentes e jovens (Gonzaga et al. 2012).

Em outro estudo, Silva et al. (2012) verificaram que a renda domiciliar inferior a meio salário mínimo pode contribuir para que 39,6\% dos jovens de 15 a 24 anos abandonem a escola antes da conclusão do ensino médio. Quando analisado pela zona de residência, as autoras constataram que, nas áreas rurais, essa proporção aumenta para $43,4 \%$. No entanto, a probabilidade dos jovens das áreas urbanas também é bastante expressiva (38\%).

Nessa linha de pesquisa, estudos têm mostrado que a renda dos pais ou dos adultos nos domicílios pode impactar positivamente a frequência escolar e adiar a entrada dos jovens no mercado de trabalho. Cabanas et al. (2014) mostraram que o efeito da renda dos pais pode levar ao crescimento da proporção de jovens que dedica mais tempo aos estudos, sem a necessidade de que eles ofertem sua força de trabalho ou aloquem seu tempo entre trabalhar e estudar. No entanto, os autores chamam atenção para um efeito negativo no crescimento da renda dos pais, que seria o aumento da proporção de jovens inativos, ou seja, que não "estuda e não trabalha". Os autores também observaram a influência positiva para a frequência escolar dos jovens, dada a presença de idosos no domićlio. Embora não fique claro, tendo em vista as variáveis inseridas no modelo pelos pesquisadores, esse efeito pode estar diretamente relacionado à renda de aposentadorias e/ou pensões recebidas por esses indivíduos.

Segundo os estudos citados anteriormente, a renda dos adultos dos domicílios é um dos principais fatores que aumenta a probabilidade de os jovens apenas estudarem, mesmo que outras variáveis possam impactar nessa decisão. Esse efeito pode estar relacionado à alocação intrafamiliar da renda, pois, se não houver estabilidade financeira no domicílio, o custo econômico de não trabalhar, não compensa o benefício do investimento em educação (Vieira et al. 2015).

Reis \& Camargo (2007) argumentam que aposentadorias e pensões são as principais fontes de renda provenientes de não trabalho que oferecem incentivos para os trabalhadores reduzirem suas participações no mercado de trabalho. Afirmam ainda que esses rendimentos podem influenciar não apenas o comportamento dos próprios beneficiários, mas também nas decisões de oferta de trabalho de todos os demais integrantes do domicílio, pela transfe- 
rência intradomiliciar.

Os autores analisaram como a renda domiciliar recebida por aposentados ou pensionistas influenciam nas decisões relacionadas à oferta de trabalho e frequência à escola dos jovens com idade de 15 a 21 anos. Encontraram evidências de que uma elevada renda domiciliar per capita proveniente de aposentadorias e/ou pensões reduz a probabilidade de participação do jovem no mercado de trabalho e aumenta as chances deles estarem apenas estudando ou as duas situações simultaneamente. Dessa forma, esses rendimentos podem ter um efeito positivo sobre a acumulação de capital humano dos jovens no domicílio. Entretanto, os resultados também indicaram um efeito negativo desses beneficiários sobre esses jovens, pois maiores rendimentos de aposentadorias e pensões podem aumentar a proporção de jovens que não está estudando e que não está trabalhando.

Hoffmann (2010), ao criticar o trabalho de Reis \& Camargo (2007), verificou que o efeito de um acréscimo na renda de aposentadorias e/ou pensões é cerca de duas vezes maior do que o efeito de um acréscimo de igual montante na renda de outras fontes na probabilidade de participação do jovem na PEA. Verificou ainda que a presença de aposentados e/ou pensionistas no domicílio contribui com a redução da probabilidade de o jovem "trabalhar e não estudar", aumenta substancialmente a probabilidade de "estudar e não trabalhar" e reduz a probabilidade de "não estudar e não trabalhar". Ao contrário do que afirmam Reis \& Camargo (2007), o autor concluiu que a probabilidade de o jovem estar na categoria "nem-nem" é menos sensível ao nível dos rendimentos de aposentadorias e pensões. No entanto, os resultados encontrados indicam que a presença de aposentados e/ou pensionistas no domicílio contribui para reduzir essa probabilidade.

Outras importantes fontes de renda e auxílio à população, sobretudo, às famílias pobres, são os programas de transferências de renda, como o PBF e o Programa de Erradicação do Trabalho Infantil (PETI). Voltados para famílias carentes, o objetivo dessas políticas é eliminar ou amenizar, em curto prazo, as dificuldades acarretadas pela condição de pobreza. Ao promover as transferências de renda direta - dadas as condicionalidades de participação, como frequência escolar, atendimento médico, etc. - esses programas apresentam dois aspectos que caracterizam uma estratégia de interromper a reprodução do ciclo da pobreza entre gerações: a garantia de renda mínima de subsistência das famílias pobres e resguardar a obtenção de capital humano aos beneficiários (Cacciamali et al. 2010).

Como grande parte dos estudos na literatura analisam o impacto do Programa Bolsa Família (PBF) e PETI apenas sobre o trabalho infantil e a frequência escolar de crianças e adolescentes, não é possível dizer qual o seu efeito sobre comportamento dos jovens de 15 a 21 anos, aspecto que será analisado neste estudo ${ }^{3}$.

\footnotetext{
${ }^{3}$ Para mais detalhes sobre o impacto do PBF sobre o trabalho infantil e frequência escolar consultar Cacciamali et al. (2010), Nascimento \& Kassouf (2016), Pedroso \& Côrrea (2015), Pedroso \& Côrrea (2014)
} 


\subsection{Aposentadorias, Pensões e Programas Sociais no Brasil}

O sistema previdenciário social do Brasil é um dos mais importantes instrumentos de política pública e base de sustentação econômica de grande parte dos pequenos municípios brasileiros de baixa renda (Ferreira \& Souza 2007). Regulamentado pela Constituição Federal, o Regime Geral da Previdência Social (RGPS) divide-se em dois sistemas: o sistema de previdência urbana, vinculado ao contrato formal de trabalho, nos moldes de um seguro social contratual; e a previdência rural que reconhece o trabalho informal em regime de economia familiar como fonte legitimadora dos diretos previdenciários dos trabalhadores rurais (Delgado \& Castro 2003).

Grande parte dos direitos previdenciários do Brasil foi definida na Constituição de 1988, na qual novos parâmetros foram definidos para a população rural. As principais mudanças ocorridas a partir da aprovação da Constituição, que foi efetivamente implementada a partir de 1992, estabeleceram: i) a universalização do benefício para toda população de idosos e inválidos residentes no meio rural (o antigo regime previdenciário beneficiava apenas o cabeça do casal); ii) a redução do limite de idade para aposentadorias por idade (para os homens, reduziu de 65 para 60 anos e mulheres aos 55 anos de idade) e; iii) o estabelecimento de um piso de aposentadorias e pensões em um salário mínimo (o regime anterior estabelecia um teto de meio salário mínimo, a menos que a aposentadoria fosse por invalidez ou acidente de trabalho que era de 3/4 do salário mínimo) (Delgado \& Cardoso JR 1999).

Já o direito a pensões é cedido ao cônjuge, ao companheiro ou à companheira (em união estável em no mínimo dois anos) desde que sejam comprovados, a filhos menores de 21 anos e a dependentes com deficiência ou invalidez (como filhos maiores de 21 anos, irmãos e pais que comprovem que não podem se sustentar ou quem os sustentem $)^{4}$.

Portanto, os benefícios oriundos de aposentadorias por idade (ou invalidez) e pensões é uma importante fonte de renda para as famílias brasileiras, que garante o meio de subsistência para suprir as necessidades vitais de sobrevivência dos inativos e de seus dependentes diretos (Delgado \& Cardoso JR 1999).

Dos programas sociais de transferência condicionada a renda desenvolvidos no Brasil, dois merecem destaque, o Programa Bolsa Família e o Programa de Erradicação do Trabalho Infantil (PETI). O PBF foi criado em 2003, com o objetivo de contribuir com o combate à pobreza e a desigualdade de renda das famílias brasileiras. Ele possui três eixos principais: complemento da renda (as famílias recebem um benefício em dinheiro, que é transferido diretamente do Governo Federal); acesso a direitos (as famílias devem cumprir alguns compromissos (condicionalidades), que têm como objetivo reforçar o acesso à educação, à saúde e à assistência social) e; articulação com outras ações (integração e articulação com outras políticas sociais, a fim de estimular o desenvolvimento das famílias, contribuindo para superarem a situação de vulnerabilidade e de

\footnotetext{
${ }^{4} \mathrm{Em} 2015$ as regras para os beneficiários de pensões por morte foram alteradas podendo ser consultada na Lei ${ }^{\circ} 13.135$, de 17 de junho de 2015.
} 
pobreza) (Brasil 2016).

O PETI é um programa do Governo Federal que tem por objetivo erradicar o trabalho infanto-juvenil dos menores de 16 anos de idade e garantir a frequência escolar e a atividades socioeducativas de crianças e adolescentes. Os valores monetários da bolsa mensal, pagos às famílias variam de $\mathrm{R} \$ 25,00$ por criança em atividade para a família que retirar a criança do trabalho, em municípios, na área rural ou urbana, com população de 250 mil habitantes. E de $\mathrm{R} \$ 40,00$ por criança, em atividade na zona urbana, em regiões metropolitanas e municípios com população superior a 250 mil habitantes (Brasil 2016)

Os benefícios oferecidos por esses programas podem alterar a oferta de trabalho dos jovens, principalmente dos adolescentes em idade escolar, na medida em que oferecem incentivos financeiros para a permanência destes na escola. A suposição é de que a assistência financeira às famílias modificaria os custos de oportunidade que banalizam as "decisões familiares" acerca da alocação do tempo de seus filhos (Araújo et al. 2010).

\section{Metodologia e Base de Dados}

\subsection{Base de Dados}

Os dados utilizados neste estudo fazem parte da Pesquisa Nacional por Amostra de Domicílios (PNAD) de 2014, realizadas anualmente pelo Instituto Brasileiro de Geografia e Estatística (IBGE), que coleta informações dos residentes dos domicílios em todo o território brasileiro. Foram selecionados domicílios em cuja composição familiar existia pelo menos um jovem com idade de 15 a 21 anos. Foram considerados todos os moradores dos domicílios, exceto pensionistas ${ }^{5}$, empregados domésticos e os parentes dos empregados domésticos das áreas urbanas e rurais. O grupo de tratamento é definido pelos domicílios em que existe, pelo menos, um beneficiário de aposentadorias e/ou pensões ${ }^{6} \mathrm{e}$ que recebem rendimentos de programas sociais. O impacto de tais rendimentos será observado sobre a situação da frequência pescolar e da participação do jovem no mercado de trabalho em quatro categorias: estuda e participa da PEA, só estuda, só participa da PEA e não estuda e não participa da PEA (“nem-nem").

As variáveis explicativas foram geradas levando em conta os critérios de seleção para cada grupo de tratamento, primeiramente as variáveis observáveis selecionadas para descrever os domicílios do grupo de tratamento de aposentadorias e pensões e do grupo de controle para definir o Propensity Score como classificadas na Tabela 1.

Para selecionar os beneficiários de programas sociais foram seguidos alguns critérios, visto que, na PNAD, não é possível selecionar com perfeição os indivíduos que recebem Bolsa Família e PETI ou parcelas de outros programas sociais. O primeiro passo foi identificar os beneficiários do PBF. Para

\footnotetext{
${ }^{5}$ Morador residente em domicílio particular que, sem ser parente, pagava hospedagem.

${ }^{6}$ Aposentadorias e pensões de fontes públicas (INSS, estatual ou municipal) e privadas.
} 
Tabela 1: Descrição das variáveis utilizadas para o matching de aposentadorias e pensões

\begin{tabular}{|c|c|}
\hline Variáveis & Descrições \\
\hline \multicolumn{2}{|c|}{ Características dos moradores do domicílio } \\
\hline Mulheres maiores 55 & $\begin{array}{l}\text { Dummy que indica a presença de pessoas do sexo feminino com idade igual ou superior a } 55 \text { anos de idade }{ }^{7} \text { (1-sim; } 0 \text {-caso } \\
\text { contrário (c.c.)) }\end{array}$ \\
\hline Homens maiores 60 & $\begin{array}{l}\text { Dummy que indica se a presença de pessoas do sexo masculino com idade igual ou superior a } 60 \text { anos de idade }{ }^{8} \text { (1-sim; } \\
\text { 0-c.c.) }\end{array}$ \\
\hline Viúvos & Dummy que indica a presença de indivíduos viúvos no domicílio (1-sim; 0-c.c.) \\
\hline Sem instrução & $\mathrm{N}^{\mathrm{o}}$ de pessoas no domicílio sem instrução ou não alfabetizadas \\
\hline Educação 1 a 3 & $\mathrm{~N}^{\mathrm{o}}$ de pessoas no domicílio que tem de 1 a 3 anos de estudos \\
\hline Educação 4 a 7 & $\mathrm{~N}^{\mathrm{o}}$ de pessoas no domicílio que tem de 4 a 7 anos de estudo \\
\hline Educacão 8 a 10 & $\mathrm{~N}^{\circ}$ de pessoas no domićlilio que tem de 8 a 11 anos de estudos (ensino fundamental completo) \\
\hline Educação mais de 11 & No de pessoas no domicílio com mais de 11 anos de estudo (ensino médio completo). \\
\hline \multicolumn{2}{|l|}{ Composição familiar } \\
\hline Crianças menores 5 & $\mathrm{~N}^{\circ}$ de crianças no domicílio menores de 5 anos de idade \\
\hline Crianças 6 a 10 & $\mathrm{~N}^{\circ}$ de crianças no domicílio com idade entre 6 a 10 anos de idade \\
\hline Crianças 11 a 14 & $\mathrm{~N}^{\circ}$ de crianças no domicílio com idade entre 11 e 14 anos \\
\hline Adolescentes 15 a 21 & $\mathrm{~N}^{\circ}$ de jovens no domicílio com idade entre 15 e 21 anos \\
\hline \multicolumn{2}{|c|}{ Característica da pessoa de referência no domicílio e rendimentos } \\
\hline Idade chefe & Idade do chefe do domicílio \\
\hline Chefe branco & Dummy que indica a cor do chefe do domicílio (1-branco; 0-c.c.) \\
\hline Chefe agricultor & Dummy indicando se o chefe do domicílio trabalha na agricultura (1-sim; 0-c.c.) \\
\hline Trabalhador principal & Renda domiciliar per capita do domicílio cujo rendimento é oriundo do trabalho principal, excluindo a renda dos jovens \\
\hline
\end{tabular}


tanto foi utilizada a metodologia criada por Barros et al. (2007a) e usada por Nascimento \& Kassouf (2014), com base em valores típicos.

Os beneficiários do PBF recebem benefícios classificados em quatro grupos. O grupo de Benefício Básico, destinado às famílias em situação de extrema pobreza, sem filhos ou crianças e adolescentes presentes no domicílio (valores fixos - R\$ 77,00); O segundo grupo é o de Benefícios Variáveis, pago às famílias com renda mensal per capita de até $\mathrm{R} \$ 154,00$, no valor de $\mathrm{R} \$ 35,00 /$ pessoa (até o limite máximo de cinco pessoas por família) e que atendam aos seguintes critérios: i) presença de crianças ou adolescentes de 0 a 15 anos de idade, sendo exigida a frequência escolar das crianças e adolescentes de 6 a 15 anos; ii) gestantes; iii) nutrizes - famílias que tenham crianças com idade entre 0 e 6 meses em sua composição, mesmo nos casos em que o bebê não more com a mãe. O terceiro grupo é de Benefício Variável Vinculado ao Adolescente, no valor de $\mathrm{R} \$ 42,00 /$ adolescente com limite máximo de dois por família, pago às famílias pobres e extremamente pobres que tenham em sua composição, adolescentes com idade de 16 e 17 anos. O quarto grupo é o de Benefício para Superação da Extrema Pobreza, em valor calculado individualmente para cada família, pago às famílias que continuem com renda mensal por pessoa inferior a $\mathrm{R} \$ 77,00$, mesmo após receberem outros tipos de benefícios do programa. $\mathrm{O}$ valor do benefício é calculado de acordo com a renda e quantidade de pessoas da família, para garantir que a família ultrapasse o piso de $\mathrm{R} \$ 77,00$ de renda por pessoa9 $(\mathrm{MDS}, 2015)$.

Portanto, atualizando os valores do PBF, a partir do Decreto $n^{\circ} 8.232$ de 30 de abril de 2014, aqueles recebidos por família dada a sua composição estão apresentados na Tabela 1 .

Adotado esses critérios, o segundo passo era identificar os valores pagos pelo PBF aos beneficiários nos meses de agosto e setembro de 2014 (mês anterior à realização da pesquisa PNAD e mês em que a pesquisa foi realizada, respectivamente). Além disso, tinha-se que identificar os valores recebidos por beneficiários do Programa de Erradicação do Trabalho Infantil (PETI).

Segundo informações coletas no site do Ministério de Desenvolvimento Social e Agrário (MDS), os valores pagos pelo PBF nos meses de agosto e setembro de 2014 variaram entre $R \$ 35,00$ e $R \$ 1.562,00$ e os valores pagos aos beneficiários do PETI, entre $\mathrm{R} \$ 25,00$ a $200,00^{10}$, sendo que foram selecionados dentro da variável V1273 da base de dados da PNAD.

No entanto, essa seleção apresenta algumas limitações, como explica Soares et al. (2010). Isto porque as rendas do Programa de Erradicação do Trabalho Infantil (PETI), do Auxílio-Gás, do Bolsa Escola, do Bolsa Alimentação, do Cartão Alimentação e do Bolsa Família, além de programas estaduais ou municipais estão capturadas na variável residual V1273: "Juros de caderneta de

\footnotetext{
${ }^{9}$ Fonte dos dados disponível em: <http://mds.gov.br/assuntos/bolsa-familia/o-quee/beneficios>. Acesso em: 23 set. 2016.

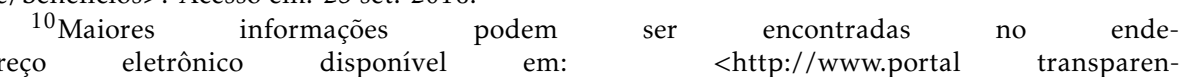
cia.gov.br/downloads/mensal.asp?c=BolsaFamiliaFolhaPagamento $>$. Acesso em: 23 set. 2016.
} 
Tabela 2: Valores dos beneficiários do Bolsa Família conforme o número de crianças e adolescentes no domicílio

\begin{tabular}{|c|c|c|}
\hline Número de Filhos & $\begin{array}{l}\text { Famílias Extremamente Pobres - Renda } \\
\text { per capita - Até } \mathrm{R} \$ 77\end{array}$ & Famílias Pobres - Renda per capita - Até R\$154 \\
\hline Sem filhos & $\mathrm{R} \$ 77$ & - \\
\hline 1 filho até 15 anos & $\mathrm{R} \$ 112$ & $\mathrm{R} \$ 35$ \\
\hline 2 filhos até 15 anos & $\mathrm{R} \$ 147$ & $\mathrm{R} \$ 70$ \\
\hline 3 filhos até 15 anos & $\mathrm{R} \$ 182$ & $\mathrm{R} \$ 105$ \\
\hline 1 filho de 16 a 17 anos & $\mathrm{R} \$ 115$ & $\mathrm{R} \$ 42$ \\
\hline 2 filhos de 16 a 17 anos & $\mathrm{R} \$ 153$ & $\mathrm{R} \$ 84$ \\
\hline 1 filho até 15 anos + 1 filho 16 a 17 anos & $\mathrm{R} \$ 189$ & $\mathrm{R} \$ 77$ \\
\hline 1 filho até 15 anos +2 filhos 16 a 17 anos & $\mathrm{R} \$ 266$ & $\mathrm{R} \$ 119$ \\
\hline 2 filhos até 15 anos +1 filho 16 a 17 anos & $\mathrm{R} \$ 294$ & $\mathrm{R} \$ 112$ \\
\hline 2 filhos até 15 anos +2 filhos 16 a 17 anos & $\mathrm{R} \$ 343$ & $\mathrm{R} \$ 154$ \\
\hline 3 filhos até 15 anos + 1 filho 16 a 17 anos & $\mathrm{R} \$ 413$ & $\mathrm{R} \$ 147$ \\
\hline 3 filhos até 15 anos +2 filhos 16 a 17 anos & $\mathrm{R} \$ 483$ & $\mathrm{R} \$ 189$ \\
\hline
\end{tabular}

Fonte: BRASIL (2015): adaptado de NASCIMENTO (2013) com valores atualizados.
Nota: Famílias pobres sem filhos não são elegíveis para o recebimento do bolsa família, apenas famílias em situação de extrema pobreza. 
poupança e de outras aplicações financeiras, dividendos, programas sociais e outros rendimentos que recebia, normalmente, no mês de referência" (Brasil 2014). Trata-se de uma categoria de rendimento absurdamente heterogênea, logo, em um mesmo valor podem estar incorporados vários programas sociais ou até mesmo os rendimentos de taxa de juros.

O segundo problema apresentado por essa estratégia de identificação é que as pessoas erram e arredondam suas rendas para valores superiores ou inferiores. É também possível que um beneficiário do programa em questão tenha recebido outra renda classificável na variável V1273, ocultando a renda do PBF na soma. A solução mais óbvia é ampliar os valores típicos, incluindo valores arredondados e valores de outros programas que seja possível identificar (Soares et al. 2010). No entanto, como mostram Foguel \& Barros (2010), essa estratégia subestima a focalização dos benefícios relativa ao uso de outras pesquisas, como de suplementos da PNAD e censos demográficos que identificam perfeitamente essa variável. Foi necessário, portanto, identificar outras características dos indivíduos e de suas famílias, que pudessem aproximar o máximo possível dos valores reais. Portanto, além dos valores típicos dos programas sociais, foram selecionadas características dos domicílios, tais como renda familiar per capita, subtraídos os valores presente na variável V1273 e a presença de crianças e adolescente de 0 a 17 anos, sendo o perfil de seleção da maioria indivíduos dos programas sociais de transferência de renda.

Além disso, em 2014, a PNAD trouxe junto de seu questionário um suplemento sobre a Cadastro Único (Cadúnico) de Programas Sociais, no qual perguntou aos moradores entrevistados se haviam tentado fazer cadastramento que dá acesso a algum programa social, com essa informação foram excluídos aqueles que informaram nunca ter tentado se cadastrar no Cadúnico.

Feito isso, no Tabela 3 são apresentadas as variáveis selecionadas para o pareamento dos tratados e não tratados dos programas sociais que relacionam outras variáveis que não estão incorporadas nas informações coletadas para o tratamento de aposentadorias e pensões. Visto que a elegibilidade dos beneficiários de programas sociais segue critérios relacionados à vulnerabilidade das famílias, foram selecionadas variáveis usadas com bastante frequência na literatura em análises do PBF e do PETI.

\subsection{Estratégia Empírica}

\section{Algoritmo CEM}

Um problema associado aos métodos de matching baseados no Propensity Score ${ }^{11}$ é o seu fraco desempenho em encontrar grupos de comparação equilibrados. De fato, o alvo principal dos métodos de matching consiste em eliminar observações de modo a obter um melhor equilíbrio comparativo entre grupos tratados e o grupo de controle (Iacus et al. 2011).

Para tentar contornar esses problemas, Iacus \& King (2009) desenvolveram o algoritmo Coarsened Exact Matching (CEM), o qual não exige nenhuma

\footnotetext{
${ }^{11}$ Propensity Score Matching (PSM) segundo Dehejia and Wahba (2002).
} 
Tabela 3: Descrição das variáveis utilizadas para o matching de programas sociais

\begin{tabular}{|c|c|}
\hline Variáveis & Descrições \\
\hline \multicolumn{2}{|c|}{ Características da pessoa de referência do domicílio } \\
\hline $\begin{array}{l}\text { Sexo chefe } \\
\text { Idade chefe } \\
\text { Cor chefe } \\
\text { Casado } \\
\text { Chefe sem instrução } \\
\text { Educação chefe de } 1 \text { a } 3 \\
\text { Educação chefe de } 4 \text { a } 7 \\
\text { Educação chefe de } 8 \text { a } 1 \\
\text { Educação chefe mais } 11 \\
\text { Chefe carteira assinada } \\
\text { Chefe sem carteira assinada } \\
\text { Responsável desempregado } \\
\text { Cônjuge trabalha }\end{array}$ & $\begin{array}{c}\text { Dummy para sexo da pessoa de referência do domicílio (1-homem; } 0 \text {-mulher) } \\
\text { Variável contínua, idade da pessoa de referência do domicílio } \\
\text { Dummy cor da pessoa de referência do domicílio (1-branca; } 0 \text {-caso contrário) } \\
\text { Dummy se a pessoa de referência no domićlí é casada (1-sim; } 0 \text {-c.c.) } \\
\text { Dummy escolaridade da pessoa de referência do domicílio (1-sem instrução; } 0 \text {-c.c.) } \\
\text { Dummy escolaridade da pessoa de referência do domicílio (1-de } 1 \text { a } 3 \text { anos de estudos; } 0 \text {-c.c.) } \\
\text { Dummy escolaridade do chefe do domicílio (1-de } 4 \text { a } 7 \text { anos de estudos; } 0 \text {-c.c.) } \\
\text { Dummy escolaridade do chefe do domićlio (1-de } 8 \text { a } 10 \text { anos de estudos; } 0 \text {-c.c.) } \\
\text { Dummy escolaridade do chefe do domicílio (1-11 anos ou mais; } 0 \text {-c.c.) } \\
\text { Dummy para o chefe do domicílio que trabalha com carteira assinada (1-sim; } 0 \text {-c.c.) } \\
\text { Dummy para o chefe do domicílio que trabalha sem carteira assinada (1-sim; } 0 \text {-c.c.) } \\
\text { my se a pessoa de referência do domicílio está desempregada e economicamente inativa (1-sim; } 0 \text {-c.c.) } \\
\text { Dummy se o cônjuge trabalha (1-sim; } 0 \text {-c.c.) }\end{array}$ \\
\hline \multicolumn{2}{|l|}{ Composição familiar } \\
\hline \multicolumn{2}{|l|}{ Características de moradia } \\
\hline $\begin{array}{l}\text { Domicílio permanente } \\
\text { Paredes adequadas } \\
\text { Cobertura adequada } \\
\text { Água canalizada } \\
\text { Saneamento adequado } \\
\text { Lixo adequado } \\
\text { Eletricidade }\end{array}$ & $\begin{array}{c}\text { Dummy se o domicílio é permanente (1-sim; 0-c.c.) } \\
\text { Dummy se o domicílio possui paredes de alvenaria (1-sim; 0-c.c.) } \\
\text { Dummy se o domicílio possui telhado de telhas ou laje (1-sim; 0-c.c.) } \\
\text { Dummy se o domicílio possui água encanada ligada a rede pública (1-sim; 0-c.c.) } \\
\text { Dummy se o domicílio possui escoadouro adequado ligado à rede pública (1-sim; 0-c.c.) } \\
\text { Dummy se o domicílio possui coleta de lixo adequado (1-sim; 0-c.c.) } \\
\text { Dummy se o domicílio possui eletricidade (1-sim; } 0 \text {-c.c.) }\end{array}$ \\
\hline
\end{tabular}

Fonte: Elaboração dos autores com base na pesquisa. 
hipótese sobre o processo de geração de dados (DGP), com exceção da ignorabilidade. Além disso, tal método garante que os desiquilíbrios entre os grupos de tratados e de controle pós o matching não sejam maiores que um limite previamente selecionado.

Iacus et al. (2011) mostraram, por meio de simulações de um grande número de DGP's, que CEM possui propriedades estatísticas superiores aos métodos tradicionais, como, por exemplo, menor desiquilíbrio entre grupos pós matching, menor dependência do modelo, dentre outros. Além disso, o CEM permite a melhora da análise de outros métodos, como o próprio PSM e Entropia, por exemplo. Diversos autores têm aplicado esse método na literatura em diversas áreas, tais como, (Aroca et al. 2014), (Datta 2015) e (Schurer et al. 2015).

O algoritmo do CEM segue os seguintes passos:

1. Dadas as covariadas $X$, é realizada uma cópia de $X$, denominada $X^{*}$;

2. $X^{*}$ é "engrossado" (coarsened), ou de acordo com cortes amostrais previamente selecionados, ou utilizando um método automático desenvolvido por Iacus \& King (2009);

3. Cria-se um estrato por unidade de observação de $X^{*}$ e se coloca cada observação no estrato;

4. Relaciona o estrato com os dados originais, $X$, e eliminam-se as observações do estrato que não contem ao menos um tratado ou uma unidade de controle.

Nesse trabalho não será utilizado o CEM para a comparação direta entre grupos de tratados e de controle, mas para melhorar o desempenho de outro método ao escolher mais adequadamente, com menos desequilíbrio, as observações a serem pareadas.

\section{Propensity Score Matching - PSM}

Após o balanceamento pelo algoritmo CEM, o próximo passo é estimar um modelo que possibilite a identificação pontual do efeito médio do tratamento (ATT). Utiliza-se, portanto, a metodologia introduzida por (Rosenbaum \& Rubin 1983), conhecida por Propensity Score Matching (PSM).

O PSM permite o pareamento do grupo de tratamento com unidades do grupo de controle, que são semelhantes em termos de suas características observáveis. Essa é uma técnica semi-paramétrica de determinação dos efeitos de um tratamento em um quase-experimento, baseada em algoritmos de pareamento de indivíduos pertencentes a grupos distintos, com o objetivo de se julgar os efeitos de uma determinada intervenção. No entanto, é necessário atender algumas suposições. A primeira delas é a Suposição de Independência Condicional (SIC) ou balanceamento nas variáveis pré-tratamento. Que é definida por (Rosenbaum \& Rubin 1983) da seguinte forma: 


$$
D \perp(Y(1), Y(0)) \mid X
$$

ou

$$
E(Y(0) \mid D=1, X)=E(Y(0) \mid D=0, X)
$$

Pela suposição $1 a$, assume-se que dadas as variáveis observáveis $X$, o tratamento $D$ não estar condicionado aos resultados potenciais de $Y(0)$ e $Y(1)$. Portanto, a equação $1 b$ reflete que o SIC, a esperança condicional do resultado potencial de $Y(0)$ em relação às variáveis observáveis $X$, que são independentes do status de tratamento $D$. Condicionadas as variáveis escolhidas, a aleatoriedade aos grupos são garantidas.

A segunda suposição estar relacionada à condição de suporte comum que pode ser representada pela seguinte equação: $0<\operatorname{Pr}\left(D_{i}=1 \mid X_{i}=x\right)<1$. Segundo Heckman et al. (1999), essa suposição garante a comparabilidade entre os grupos de tratamento e controle. Ou seja, ela assegura que entre as características observáveis $X_{i}$ do grupo de tratamento existem observações comparáveis no grupo de controle, próximas na distribuição do escore de propensão.

Outra suposição necessária para a estimação do efeito tratamento é o critério de balanceamento. Lee (2013) afirma que o balanceamento do escore de propensão é satisfeito quando, para cada valor de $X$, tem-se uma distribuição similar entre o grupo de tratamento e controle, ou seja $D \perp X \mid P(X)$. Em que $\mathrm{X}$ representa o conjunto de covariáveis que são escolhidas para satisfazer SIC. O balanceamento consiste em um teste de igualdade de média para as variáveis observáveis condicionadas ao escore de propensão. Para garantir a robustez dos resultados encontrados, neste estudo, foram testados três dos mais utilizados na literatura para o pareamento entre grupos de tratamento e controle: o vizinho mais próximo (Nearest Neighbor Matching) o alcance (Radius Matching) e Kernel, com base no estudo desenvolvido por (Becker \& Ichino 2002). Foi escolhido aquele que apresentou o melhor pareamento entre o grupo de controle e tratamento.

Finalmente, pelo teorema do escore de propensão e supondo que o SIC é atendido, o ATT resultante do pareamento direto dos valores entre grupo de tratamento e controle é dado por:

$$
\begin{array}{r}
A T T=E\left[Y_{1 i}-Y_{0 i} \mid D_{i}=1\right]=E\left\{E\left[Y_{i} \mid P\left(X_{i}\right), D_{i}=1\right]\right. \\
\left.-E\left[Y_{i} \mid P\left(X_{i}\right), D_{i}=0\right] \mid D_{i}=1\right\}
\end{array}
$$

em que $D_{i}=1$ refere-se ao tratamento.

\section{Análise de Sensibilidade}

Se variáveis não observadas afetam o processo de seleção, também afetam os resultados, então os estimadores baseados no escore de propensão não são 
estimadores consistentes do efeito do tratamento. Dessa forma, a omissão dessas variáveis pode gerar resultados do efeito médio do tratamento sobre o tratado estimado viesados. O método conhecido como Rosenbaum Bounds (Rosenbaum 2002) e (Diprete \& Gangl 2004)), permite determinar quão "forte" deve ser a influência de uma variável omitida sobre a seleção na participação.

Considerando-se que a probabilidade de participação de um indivíduo $i$ seja dada por:

$$
\pi_{i}=\operatorname{Pr}\left(D_{i}=1 \mid x_{i}\right)=F\left(\beta x_{i}+\gamma u_{i}\right)
$$

Como já explicitado $D_{i}$ é igual a 1 , se o indivíduo recebe o tratamento e 0 , caso não receba; $x_{i}$ são as características observadas do indivíduo $i$; $u_{i}$ corresponde à variável não observada e $\gamma$ representa o efeito de $u_{i}$ sobre a decisão de participação no programa. Se não existir viés de seleção, então $\gamma$ será igual a zero e a probabilidade de participação será exclusivamente determinada pelas características observáveis. Entretanto, na presença de viés de seleção, dois indivíduos com as mesmas covariáveis observadas $x$ terão diferentes chances de receber tratamento, $\frac{\theta_{i}}{1-\theta_{i}}$ e $\frac{\theta_{j}}{1-\theta_{j}}$ e a odds ratio é dada por:

$$
\frac{\frac{\theta_{i}}{1-\theta_{i}}}{\frac{\theta_{j}}{1-\theta_{j}}}=\frac{\theta_{i}\left(1-\theta_{j}\right)}{\theta_{j}\left(1-\theta_{i}\right)}=\exp \left[\gamma\left(u_{i}-u_{j}\right)\right]
$$

Se os indivíduos possuírem as mesmas características observáveis, então o vetor $x$ se cancela. Desse modo, se não houver diferenças nas variáveis não observadas $\left(u_{i}=u_{j}\right)$ e se essas variáveis não influenciarem a probabilidade de participação $(\gamma=0)$, a odds ratio será igual a 1 , implicando a não existência de viés de seleção. Segue-se então que, se suas odds de participação diferirem, isto é, se a oddsratio for diferente de 1 , só pode ser devido à presença de não observáveis. A análise de sensibilidade avalia o quanto do efeito do programa é alterado pela mudança nos valores de $\gamma$ e de $u_{i} \breve{u}_{j}$. Isso significa examinar os limites da odds ratio de participação. Rosenbaum (2002) mostra que (4) implica os seguintes limites para a odds ratio:

$$
\frac{1}{e^{\gamma}} \leq \frac{\alpha_{i}\left(1-\theta_{j}\right)}{\theta_{i}\left(1-\theta_{i}\right)} \leq e^{\gamma}
$$

Os indivíduos pareados possuem a mesma probabilidade de participação apenas se $e^{\gamma}=1$. Entretanto, se $e^{\gamma}=2$, então indivíduos aparentemente similares em termos de $x$ irão diferir nas probabilidades de receberem tratamento por um fator de até 2 .

\section{Teste de Sensibilidade}

(Millimet \& Tchernis 2012) propuseram dois novos estimadores para estimar o efeito tratamento, quando existe seleção de variáveis não observadas e as restrições de exclusão não são disponíveis. Quando existe seleção de variáveis não observadas, comumente utiliza-se a abordagem empírica de Variáveis Instrumentais (VI), contudo, se os instrumentos não são válidos, ou não estão disponíveis, foi desenvolvida uma nova técnica para solucionar esse problema 
por (Millimet \& Tchernis 2012), o qual propõe os seguintes estimadores:

\section{Estimador de viés mínimo (Minimum Biased - MB):}

Esse estimador procura minimizar o viés no efeito tratamento de interesse. Isso é feito por meio de um recorte na amostra para incluir somente as observações com escore de propensão dentro de um intervalo estabelecido pelo pesquisador. Quando a Hipótese da Independência Condicional (Conditional Independence Assumption (CIA) é satisfeita, o estimador é imparcial. Caso contrário, o MB tenderá a minimizar o viés dentre os estimadores que dependem da CIA. Vale ressaltar que o estimador MB muda os parâmetro estimados por causa da amostra restrita.

Essa técnica parte genericamente do estimador da probabilidade inversa ponderada (Inverse Probability Weighted - IPW), desenvolvido por Hirano \& Imbens (2001) dado por:

$$
\hat{\tau}_{I P W, A T E}=\frac{\sum_{i=1}^{N} \frac{Y_{i} T_{i}}{\hat{P}\left(X_{i}\right)}}{\sum_{i=1}^{N} \frac{T_{i}}{\hat{P}\left(X_{i}\right)}}-\frac{\sum_{i=1}^{N} \frac{Y_{i}\left(1-T_{i}\right)}{1-\hat{P}\left(X_{i}\right)}}{\sum_{i=1}^{N} \frac{\left(1-T_{i}\right)}{1-\hat{P}\left(X_{i}\right)}}
$$

Em que $\hat{P}\left(X_{i}\right)$ é uma estimativa do escore de propensão obtida por meio de um modelo probit. Sob a CIA, o estimador IPW em (6) fornece estimativas não viesadas de $\hat{\tau}_{I P W, A T E}$. O estimador MB visa minimizar o viés por meio das estimativas aplicadas somente a observações com escore de propensão próximo a um escore de propensão $\left(P^{*}\right)$ que minimiza o viés. Denota-se $\Omega$ ao conjunto de observações posteriormente incluídas na estimação. Em geral, contudo, $P^{*}$ e $\Omega$ não são conhecidos. O estimador $M B$, portanto, estima $P^{*}$ e $\Omega$ tal que minimize o viés utilizando modelo de seleção de Heckman's BVN ${ }^{12}$.

O estimador MB do ATE é formalmente dado por:

$$
\hat{\tau}_{M B, A T E}\left[P^{*}\right]=\frac{\sum_{i \in \Omega}^{N} \frac{Y_{i} T_{i}}{\hat{P}\left(X_{i}\right)}}{\sum_{i \in \Omega}^{N} \frac{T_{i}}{\hat{P}\left(X_{i}\right)}}-\frac{\sum_{i \in \Omega}^{N} \frac{Y_{i}\left(1-T_{i}\right)}{1-\hat{P}\left(X_{i}\right)}}{\sum_{i \in \Omega}^{N} \frac{\left(1-T_{i}\right)}{1-\hat{P}\left(X_{i}\right)}}
$$

Por meio $\Omega=i \mid \hat{P}\left(X_{i} \in C\left(P^{*}\right)\right)$ e $C(P)$ denota intervalo próximo a $P$. Seguindo Millimet \& Tchernis (2012), o estimador define $C\left(P^{*}\right)$ como $C\left(P^{*}\right)$ $=\hat{P}\left(X_{i}\right) \mid\left\{\hat{P}\left(X_{i}\right) \in(\underline{P}, \bar{P})\right\}$, em que $\underline{P}=\max \left(0.02, P^{*}-\alpha_{\theta}\right), \bar{P}=\min \left(0.98, P^{*}+\alpha_{\theta}\right)$, $\alpha_{\theta}>0$ é um valor pequeno tal que, $\theta$ porcento de ambos os grupos, tratados e controles, estejam contidos em $\Omega$.

\section{Estimador de viés corrigido (Bias Corrected - BC):}

Esse estimador parte do estimador do modelo de seleção de Heckman's Bivariate Normal (BVN) em dois estágios, a fim de minimizar o viés dentre os estimadores que aplicam a CIA de forma inapropriada (Heckman 1976) e (Heckman 1979). Contudo, ao contrário do estimador BVN, o estimador BC

\footnotetext{
${ }^{12}$ Para mais detalhes ver (Millimet \& Tchernis 2012).
} 
não requer especificação da forma funcional para o resultado de interesse na etapa final. Além disso, ao contrário do estimador $\mathrm{MB}, \mathrm{o} \mathrm{BC}$ não altera o parâmetro a ser estimado.

Estimativas do viés do estimador MB do ATE, denotado por $\hat{B}_{A T E}\left[P^{*}\right]$, pode ser derivado modelo BVN em dois estágios. A estimativa do viés pode ser aplicada ajustando a estimativa do efeito tratamento IPW.

O estimador viés mínimo/viés corrigido (Minimum Bias/Bias Corrected $\mathrm{MB} / \mathrm{BC})$ para o ATE é dado por: $\hat{\tau} M B / B C, A T E\left[P^{*}\right]=\hat{\tau} M B, A T E\left[P^{*}\right]-\hat{B}_{A T E}\left[P^{*}\right]$. Para estimação, este trabalho utilizou o comando BMTE do software Stata 13, no qual, para identificar corretamente os parâmetros de interesse, esse comando primeiro estima o estimador $\mathrm{MB} / \mathrm{BC}$ condicionado ao escore de propensão, $P(X)$. Posteriormente estima o efeito médio do tratamento, no qual o estimador do viés corrigido é dado por:

$$
\hat{\tau} B C, A T E\left[P^{*}\right]=\hat{\tau} I P W, A T E-\sum_{i} \hat{B}_{A T E}\left[\hat{P}\left(X_{i}\right)\right]
$$

\section{Resultados e Discussões}

É importante ressaltar que, para a realização das estimativas manteve-se na amostra apenas aquelas observações completas e que, na composição domiciliar da família, existia pelo menos um jovem com idade entre 15 e 21 anos. Além disso, optou-se por apresentar os resultados para cada tratamento separadamente.

\subsection{Análise Descritiva}

Na Tabela 4, são apresentadas as informações da PNAD 2014, para o Brasil, por zona de moradia (urbano e rural) dada a frequência escolar e participação dos jovens no mercado de trabalho. Os dados amostrais denotam um total de 41.415 domicílios que tinham, pelo menos, um jovem com idade entre 15 e 21 anos, sendo que 35.366 residiam em áreas urbanas e 6.158 na zona rural.

Ainda pelos resultados apresentados na Tabela 4, em torno de $50 \%$ dos jovens entre 15 e 21 anos de idade, no Brasil, participava do mercado de trabalho, tanto na zona urbana como na zona rural, em 2014, os seja, estava trabalhando ou procurando emprego ${ }^{13}$. Nas áreas urbanas, cerca de $29,36 \%$ dos jovens encontrava-se apenas participando do mercado de trabalho, enquanto $21,00 \%$ estava trabalhando e estudando, $37,00 \%$ apenas estudavam e $12,63 \%$ não estudavam e não faziam parte da PEA.

Nas áreas rurais observa-se que a proporção de jovens que apenas estudavam é menor que nas áreas urbanas, aproximadamente três pontos percen-

\footnotetext{
${ }^{13}$ Foram classificadas como ocupadas na semana de referência as pessoas que tinham trabalho durante todo ou parte desse período. Considerando aqueles com e sem carteira assinada, trabalhador não remunerado membro da família, por conta-própria, para o próprio consumo ou que estava à procura de emprego.
} 
Tabela 4: Análise descritiva das variáveis dependentes

\begin{tabular}{l|ccc|ccc}
\hline \multirow{2}{*}{ Variáveis Dependentes } & \multicolumn{4}{|c|}{ Urbano } & \multicolumn{2}{c}{ Rural } \\
\cline { 2 - 7 } & Total & $\begin{array}{c}\text { Dom. com rendi- } \\
\text { mentos de aposen- } \\
\text { tadoria e pensões }\end{array}$ & $\begin{array}{c}\text { Dom. com rendi- } \\
\text { mentos de pro- } \\
\text { gramas sociais }\end{array}$ & $\begin{array}{c}\text { Tom. com rendi- } \\
\text { Total }\end{array}$ & $\begin{array}{c}\text { Dom. com rendi- } \\
\text { mentos de aposen- } \\
\text { mentos de pro- } \\
\text { tadoria e pensões } \\
\text { gramas sociais }\end{array}$ \\
\hline Trabalha e Não Estuda & $29,360 \%$ & $25,970 \%$ & $22,890 \%$ & $29,560 \%$ & $28,200 \%$ & $22,630 \%$ \\
Estuda e Trabalha & $21,000 \%$ & $22,620 \%$ & $18,460 \%$ & $21,780 \%$ & $22,400 \%$ & $24,070 \%$ \\
Estuda e Não Trabalha & $37,000 \%$ & $39,160 \%$ & $41,850 \%$ & $33,910 \%$ & $36,400 \%$ & $39,080 \%$ \\
Não Estuda e Não Trabalha & $12,630 \%$ & $12,260 \%$ & $16,800 \%$ & $14,760 \%$ & $13,000 \%$ & $14,220 \%$ \\
Observações & 35.366 & 9.365 & 06.896 & 06.896 & 01.600 & 04.449 \\
\hline
\end{tabular}

Fonte: Elaboração dos autores com dados da PNAD 2014. 
tuais $(33,91 \%)$. Também se nota uma diferença na proporção de jovens que estão na categoria "nem-nem", cerca de dois pontos percentuais superior aos jovens das áreas urbanas.

Analisando os domicílios com aposentados e/ou pensionistas ou que recebem benefícios de programas sociais, nota-se que é menor a proporção de indivíduos jovens que apenas participa do mercado de trabalho e, por sua vez, a proporção de jovens que apenas estudava era maior nesses domicílios. Para aqueles domicílios que recebiam rendas de algum programa social, a proporção de jovens que não estudava e não trabalhava era maior que das demais categorias $(16,80 \%$ na zona urbana e $14,22 \%$ na zona rural).

\subsection{Impactos de Aposentadorias e/ou Pensões na Frequência Escolar e Oferta de Trabalho dos Jovens}

Para encontrar o efeito das aposentadorias e/ou pensões sobre o comportamento dos jovens, quanto à sua frequência e oferta de trabalho foi realizado, primeiramente, o balanceamento das variáveis observáveis pelo método CEM, a fim de permitir que o grupo de tratamento e controle fosse o mais semelhante possível. Em seguida foi aplicado o método de pareamento pelo Propensity Score.

Na Tabela 5 são apresentados os resultados do desequilíbrio global ${ }^{14}$ entre as covariáveis do grupo de controle e tratamento para a zona urbana e rural, antes e após a aplicação do algoritmo CEM, bem como o total de observações pareadas e não pareadas após o balanceamento. Considerando os resultados de desequilíbrio (estatística $\mathcal{L}_{1}=0,58445251$ no urbano e $\mathcal{L}_{1}=0,75465171$ no rural, antes do balanceamento a estatística $\mathcal{L}_{1}=0,50636665$ no urbano e $\mathcal{L}_{1}=0,6182145$ no rural após o balanceamento), nota-se que houve uma redução dessa medida entre as covariáveis dos dois grupos, demostrando que a aplicação desse algoritmo aprimorou o equilíbrio entre tratados e não tratados. Portanto, a amostra a partir desse método passou a ser de 9.035 para tratados, no meio urbano e 1.301 na zona rural, e para os grupos de controle, 25.883 na área urbana e 4.494 na zona rural.

Após o balanceamento pelo algoritmo CEM, foi estimado o modelo logit, dada a condicionalidade que no domicílio existe a presença de, pelo menos, um aposentado e/ou pensionista. Esse procedimento permite encontrar um suporte comum entre os grupos analisados. Os resultados do modelo podem ser consultados no Apêndice, na Tabela 11, por situação censitária (urbano e rural). Posteriormente, foi testado qual dos algoritmos do PSM deveria ser usado para análise do ATT, sendo que os resultados estão expostos na Tabela 12 no Apêndice. Pelos algoritmos testados, o pareamento por Kernel ${ }^{15}$ foi es-

\footnotetext{
${ }^{14} \mathrm{O}$ desequilíbrio global é dada pela estatística $L_{1}$, sendo determinado na diferença entre o histograma $\mathcal{L}_{1}$ multidimensional de todas as covariáveis de pré-tratamento do grupo tratado e do grupo de controle. Quanto mais próximo for $\mathcal{L}_{1}=0$, mais balanceados estarão os dois grupos, quanto mais próximo for $\mathcal{L}_{1}=1$ mais separados são os tratados e controle.

${ }^{15} \mathrm{O}$ matching Kernel e Alcance apresentaram o mesmo balanceamento, porém, o Kernel foi escolhido por não apresentar no pareamento domicílios com escores de propensões diferentes. Dessa forma, o grupo dos tratados e de controle serão mais homogêneos.
} 
Tabela 5: Balanceamento CEM - tratamento, aposentadorias e/ou pensões

\begin{tabular}{l|rr|rr}
\hline \multicolumn{1}{c}{ Distância Multivariada } & \multicolumn{2}{c|}{ Urbano } & \multicolumn{2}{c}{ Rural } \\
\hline $\mathcal{L}_{1}$ - Antes do CEM & \multicolumn{2}{c}{0,5844525} & \multicolumn{2}{c}{0,7546517} \\
$\mathcal{L}_{1}$ - Após o CEM & \multicolumn{2}{c}{0,5063667} & \multicolumn{2}{c}{0,6182145} \\
\hline \multirow{2}{*}{ Algoritmo CEM } & \multicolumn{1}{c}{ Tratados } & Controle & Tratados & Controle \\
\cline { 2 - 5 } & 1 & 0 & 1 & 0 \\
\hline Total de Observações & 9.365 & 26.001 & 1.600 & 4.558 \\
Comparáveis - Após o CEM & 9.035 & 25.883 & 1.301 & 4.494 \\
Não Comparáveis - Após o CEM & 330 & 118 & 299 & 64 \\
\hline
\end{tabular}

Fonte: Dados de pesquisa. Elaboração dos autores.

colhido para análise.

$\mathrm{Na}$ Tabela 4 encontram-se os resultados do impacto de aposentadorias e pensões sobre as variáveis de frequência escolar e situação de trabalho da população jovem, considerando-se a área de residência. O ATT encontrado pelo modelo representa a diferença na frequência e oferta de trabalho dos jovens nos domicílios analisados dado o impacto do tratamento.

Para o Brasil urbano, os resultados mostram que o impacto de aposentadorias sobre os jovens que apenas estão inseridos na PEA é, em média, de 4,6 pontos percentuais, ou seja, dos domicílios onde existe pelo menos um aposentado, os jovens tendem a diminuir sua oferta de mão de obra para o mercado de trabalho. Por outro lado, aumenta a probabilidade de o jovem estar apenas estudando, isto é, em domicílios em que há aposentados, aumentam as chances de o jovem apenas frequentar a escola em, 3,0 pontos percentuais e de trabalharem e estudarem, simultaneamente, em 2,6 pontos percentuais. A categoria "não estuda e não trabalha" não foi estatisticamente significativa ao nível de 5\%. Na zona rural, nenhum dos ATTs foi estatisticamente significativo para as decisões dos jovens quanto à frequência escolar e a oferta de mão de obra.

Após verificar o efeito de aposentadorias e pensões na oferta de trabalho e frequência escolar dos jovens pelo PSM, o próximo passo foi aplicar a análise de sensibilidade discutida por Caliendo \& Becker (2007), a partir da metodologia desenvolvida por Rosenbaum (2002) conhecida por Rosenbaum Bounds, para testar a robustez dos resultados encontrados sobre a Hipótese de Independência Condicional (CIA). Isto para que se pudesse avaliar a sensibilidade dos impactos estimados em relação aos desvios da suposição de independência. Se ocorrer variáveis não observáveis que afetam a elegibilidade do tratamento e as variáveis de resultado, simultaneamente, um viés oculto pode surgir para o qual os estimadores de pareamento não são válidos.

Na Tabela 5 foram mostradas as análises do gamma $(\Gamma=1)$ dada a probabilidade de os resultados obtidos no PSM serem afetados por variáveis não observadas e que não estão no modelo. Assim, os valores $p_{m h}$ representam o nível de significância da probabilidade de variáveis omitidas estejam superestimando ou subestimando o efeito tratamento. Portanto, observa-se que a 
Tabela 6: Resultados das estimativas de propensity score matching para as variáveis binárias de frequência escolar e trabalho - rural e urbano (tratamento, aposentadorias e pensões)

\begin{tabular}{|c|c|c|c|c|c|c|c|c|c|c|}
\hline \multirow{2}{*}{ Situação de Estudo e Trabalho } & \multicolumn{5}{|c|}{ Urbano $^{(1)}$} & \multicolumn{5}{|c|}{ Rural $^{(1)}$} \\
\hline & Trat. & Cont. & ATT & EP & Test $t$ & Trat. & Cont. & ATT & EP & Test $t$ \\
\hline Trabalha e Não Estuda & 0,260 & 0,306 & $-0,046$ & 0,010 & $-4,59$ & 0,277 & 0,293 & $-0,016$ & 0,028 & $-0,58$ \\
\hline Trabalha e Estuda & 0,228 & 0,202 & 0,026 & 0,009 & 2,91 & 0,220 & 0,217 & 0,003 & 0,025 & 0,12 \\
\hline Estuda e Não Trabalha & 0,391 & 0,360 & 0,030 & 0,011 & 2,87 & 0,376 & 0,328 & 0,048 & 0,029 & 1,64 \\
\hline Não Estuda e Não Trabalha & 0,122 & 0,132 & $-0,010$ & 0,007 & $-1,43$ & 0,126 & 0,161 & $-0,034$ & 0,022 & $-1,59$ \\
\hline
\end{tabular}

Fonte: Resultado da pesquisa. Elaboração dos autores.

Nota: Em negrito, valores estatisticamente significativos a 5\%. (1) Pareamento pelo algoritmo Kernel. 
Tabela 7: Análise de sensibilidade (Rosenbaum Bounds) para frequência escolar e trabalho dos jovens: rural e urbano

\begin{tabular}{l|c|c|c|c}
\hline \multirow{2}{*}{ Situação de Estudo e Trabalho } & \multicolumn{2}{|c|}{ Urbano } & \multicolumn{2}{c}{ Rural } \\
\cline { 2 - 5 } & Q_mh & p_mh & Q_mh & p_mh \\
\hline Trabalha e Não Estuda & 8,432 & 0,000 & 1,421 & 0,078 \\
Trabalha e Estuda & 4,736 & 0,000 & 0,251 & 0,401 \\
Estuda e Não Trabalha & 5,033 & 0,000 & 2,941 & 0,002 \\
Não Estuda e Não Trabalha & 0,550 & 0,061 & 2,397 & 0,008 \\
\hline
\end{tabular}

Fonte: Resultado da pesquisa. Elaboração dos autores.

categoria "nem-nem", na zona urbana, foi a única que não foi estatisticamente significativa. Nas áreas rurais, as variáveis "estuda e não trabalha" e "não estuda e não trabalha" foram significativas e mostraram que existe uma possível superestimação ou subestimação nos resultados dessas variáveis, sendo necessário corrigir pelo viés mínimo e viés corrigido.

Portanto, considerando os resultados encontrados pode-se assumir previamente que variáveis omitidas importantes no modelo podem afetar os resultados encontrados e a probabilidade do domicílio ter indivíduos elegíveis a condição de aposentado e/ou pensionista, sobretudo, em relação aos resultados encontrados na categoria "nem-nem" no meio urbano e "trabalha e não estuda" e "estuda e trabalha" na zona rural. No entanto, pode ser que essas variáveis omitidas não sejam totalmente responsáveis pelo viés nos resultados encontrados. Ou seja, pode acontecer que o impacto dessas variáveis seja próximo de zero, de modo que toda a análise feita até aqui esteja correta. Em outras palavras, que aposentadorias e pensões não afetam as decisões dos jovens quanto a trabalhar e estudar no meio rural e dos jovens que se encontram inativos no meio urbano.

Para verificar se os resultados da análise de sensibilidade se confirmam, e analisar o viés relacionado à falha da hipótese de independência condicional (CIA), aplicou-se a técnica desenvolvida por Millimet \& Tchernis (2012). Os resultados estão apresentados na Tabela 6 , em que $\beta_{M B}$ e $\beta_{M B / B C}$ representam o viés mínimo e viés corrigido, respectivamente, do tratamento (aposentadorias e pensões) sobre as decisões dos jovens quanto à frequência escolar e oferta de mão de obra.

De acordo com os resultados encontrados, observa-se que o ATT pelo viés corrigido é estatisticamente significativo e positivo em relação à inatividade dos jovens, dada a presença de aposentados e/ou pensionistas no domicílio, no meio urbano. No meio rural, nenhum dos resultados foi estatisticamente significativo, de modo que nada se pode afirmar em relação aos resultados encontrados.

\subsection{Impactos de Programas Sociais na Frequência Escolar e Oferta de Trabalho dos Jovens}

Seguindo o método adotado por Barros et al. (2007b) foram selecionados para o grupo de tratamento 9.224 famílias que atendiam ao perfil de beneficiários 
Tabela 8: Efeito das aposentadorias/pensões sobre frequência escolar e trabalho dos jovens: estimativas do ATT sobre o viés mínimo e viés corrigido - rural e urbano

\begin{tabular}{|c|c|c|c|c|c|}
\hline \multirow{2}{*}{$\begin{array}{c}\text { Situação de Estu- } \\
\text { do e Trabalho }\end{array}$} & \multirow{2}{*}{ Theta } & \multicolumn{2}{|c|}{ Urbano } & \multicolumn{2}{|c|}{ Rural } \\
\hline & & $\beta_{\mathbf{M B}}$ & $\beta_{\mathrm{MB} / \mathrm{BC}}$ & $\beta_{\mathbf{M B}}$ & $\beta_{\mathrm{MB} / \mathrm{BC}}$ \\
\hline $\begin{array}{l}\text { Trabalha e } \\
\text { Não Estuda }\end{array}$ & 0,25 & $\begin{array}{l}- \\
- \\
- \\
-\end{array}$ & $\begin{array}{l}- \\
- \\
- \\
-\end{array}$ & $\begin{array}{c}-0,037 \\
{[-0,113 ; 0,020]} \\
-0,042 \\
{[-0,092 ; 0,012]}\end{array}$ & $\begin{array}{c}0,118 \\
{[-0,129 ; 0,348]} \\
0,113 \\
{[-0,098 ; 0,339]}\end{array}$ \\
\hline $\begin{array}{c}\text { Trabalha e } \\
\text { Estuda }\end{array}$ & 0,05 & $\begin{array}{l}- \\
- \\
- \\
-\end{array}$ & $\begin{array}{l}- \\
- \\
- \\
-\end{array}$ & $\begin{array}{c}0,029 \\
{[-0,028 ; 0,075]} \\
0,029 \\
{[-0,033 ; 0,073]}\end{array}$ & $\begin{array}{c}-0,055 \\
{[-0,248,0,133]} \\
-0,055 \\
{[-0,259 ; 0,108]}\end{array}$ \\
\hline $\begin{array}{l}\text { Não Estuda e } \\
\text { Não Trabalha }\end{array}$ & 0,25 & $\begin{array}{c}0,011 \\
{[-0,018 ; 0,031]} \\
-0,007 \\
{[-0,024 ; 0,004]}\end{array}$ & $\mid \begin{array}{c}0,077 \\
{[0,002 ; 0,155]} \\
0,058 \\
{[0,014 ; 0,137]}\end{array}$ & $\begin{array}{l}- \\
- \\
- \\
-\end{array}$ & $\begin{array}{l}- \\
- \\
- \\
-\end{array}$ \\
\hline
\end{tabular}

Fonte: Resultado da pesquisa. Elaboração dos autores.

de programas sociais, como o PBF e PETI, divididos entre a zona urbana e rural. Para o grupo de controle, foram selecionadas famílias consideradas elegíveis, mas que não recebem nenhum dos benefícios citados. Assim foram selecionadas 10.330 famílias.

Realizando os mesmos procedimentos da análise anterior, foi feito o balanceamento pelo algoritmo CEM das variáveis observáveis do grupo de tratamento e controle para a zona urbana e rural que estão expostos na Tabela 7, assim como o total das observações pareadas e não pareadas após o balanceamento.

Tabela 9: Balanceamento CEM - tratamento - programas sociais

\begin{tabular}{|c|c|c|c|c|}
\hline Distância Multivariada & \multicolumn{2}{|c|}{ Urbano } & \multicolumn{2}{|c|}{ Rural } \\
\hline $\mathcal{L}_{1}$ - Antes do CEM & \multirow{2}{*}{\multicolumn{2}{|c|}{$\begin{array}{c}0,45275522 \\
0,0000000000000004894\end{array}$}} & \multirow{2}{*}{\multicolumn{2}{|c|}{$\begin{array}{c}0,51529873 \\
0,000000000000002813\end{array}$}} \\
\hline $\mathcal{L}_{1}$ - Após o CEM & & & & \\
\hline \multirow{2}{*}{ Algoritmo CEM } & Tratados & Controle & Tratamento & Controle \\
\hline & 1 & 0 & 1 & 0 \\
\hline Total de Observações & 6.670 & 6.896 & 1.408 & 3.041 \\
\hline Comparáveis - Após o CEM & 5.022 & 5.392 & 1.328 & 2.249 \\
\hline Não comparáveis - Após o CEM & 1.648 & 1.504 & 80 & 792 \\
\hline
\end{tabular}

Fonte: Dados de Pesquisa. Elaboração Autores.

Portanto, considerando os resultados do desequilíbrio global, a estatística $\mathcal{L}_{1}=0,45275522$ no urbano e de $\mathcal{L}_{1}=0,51529873$ no meio rural, antes do balanceamento passou para valores próximos de zero após o balanceamento. Logo houve uma redução dessa medida entre as covariáveis dos dois grupos, demostrando que a aplicação desse algoritmo melhorou o equilíbrio entre tratados e controle. Assim, a amostra foi reduzida para 5.022 tratados, no meio urbano, e 1.328, na zona rural. Em relação aos grupos de controle na zona urbana e rural para, 5.392 e 2.249 , respectivamente. 
Assim, após aplicar o algoritmo CEM, foi estimado o modelo logit para encontrar o Propensity Score, tendo em vista que no domicílio existem pessoas que recebem rendimentos de programas sociais. Os resultados do modelo podem ser consultados no Apêndice, na Tabela A.1, para a zona urbana e rural. Além disso, foi testado qual dos algoritmos do PSM deveria ser usado para análise do ATT, cujos resultados estão expostos na Tabela A.2, também no Apêndice. Foi escolhido o Radius, tanto para a área urbana como a rural.

Dos resultados apresentados na Tabela 8, destaca-se que a presença de beneficiários de programas sociais apresentou sinal positivo, sendo estatisticamente significativa ao nível de 5\%, em relação àqueles jovens que apenas trabalham, trabalham e estudam simultaneamente no meio urbano. Em relação à situação de "estuda e trabalha", nenhum efeito pode ser considerando, pois não foi estatisticamente significativa. Já em relação aos jovens que residem na zona rural, a alocação entre trabalho e estudos apresentou sinal positivo e foi estatisticamente significativa. Uma possível resposta para esse efeito seria o fato de essa renda não ser suficiente para suprir as necessidades básicas da família, sendo necessário que esses jovens trabalhem para complementar a renda familiar.

Quanto ao comportamento dos jovens que não estudam e não trabalham, o sinal do ATT apresentou-se diferente do que foi observado nos rendimentos de aposentadorias e pensões. Em domicílios que recebem rendas de programas sociais, o efeito médio sobre aqueles jovens "nem-nem" é menor, em aproximadamente 3,5 pontos percentuais para urbano e 5,6 pontos percentuais para rural. Esse efeito pode estar relacionado à condição da frequência escolar das crianças e adolescentes para o recebimento do benefício, no entanto, não é possível afirmar se esse efeito se estende aos jovens com idade superior a 18 anos.

O próximo passo é aplicar a análise de sensibilidade, como mostrado na Tabela 9, para testar a robustez dos resultados encontrados, dada a hipótese de que a Suposição de Independência Condicional (SIC) não foi violada, ou seja, que variáveis não observáveis impactam nos resultados estimados.

Como pode ser observado na Tabela 9, dos resultados para a zona urbana, apenas as situações de "trabalha e não estuda" e "estuda e não trabalha" não foram estatisticamente significativas de acordo com o $p_{m} h$, sendo necessário aplicar a técnica de correção pelo viés mínimo e viés corrigido. Por outro lado, na zona rural, todos os valores do $p_{m} h$ foram estatisticamente significativos, corroborando com os resultados encontrados no PSM. Logo, não existem variáveis omitidas afetando a seletividade do grupo de tratamento e conseguintemente nos resultados, não sendo necessário aplicar a técnica de correção pelo o viés mínimo e viés corrigido.

Portanto, a Tabela 10 apresenta os resultados em relação ao viés mínimo e viés corrigido para as categorias que não foram estatisticamente significativas da zona urbana. 
Tabela 10: Resultados das estimativas de propensity score matching para as variáveis binárias de frequência escolar e trabalho - rural e urbano (tratamento programas sociais)

\begin{tabular}{|c|c|c|c|c|c|c|c|c|c|c|}
\hline \multirow{2}{*}{ Situação de Estudo e Trabalho } & \multicolumn{5}{|c|}{ Urbano $^{(1)}$} & \multicolumn{5}{|c|}{ Rural $^{(1)}$} \\
\hline & Trat. & Cont. & ATT & EP & Test $t$ & Trat. & Cont. & ATT & EP & Test $t$ \\
\hline Trabalha e Não Estuda & 0,243 & 0,216 & 0,027 & 0,009 & 2,89 & 0,233 & 0,237 & $-0,004$ & 0,022 & $-0,18$ \\
\hline Trabalha e Estuda & 0,183 & 0,157 & 0,026 & 0,008 & 3,25 & 0,234 & 0,184 & 0,050 & 0,018 & 2,84 \\
\hline Estuda e Não Trabalha & 0,411 & 0,429 & $-0,018$ & 0,011 & $-1,66$ & 0,389 & 0,379 & 0,010 & 0,022 & 0,45 \\
\hline Não Estuda e Não Trabalha & 0,163 & 0,197 & $-0,035$ & 0,009 & $-4,09$ & 0,144 & 0,200 & $-0,056$ & 0,019 & $-2,90$ \\
\hline
\end{tabular}

Fonte: Resultado da pesquisa. Elaboração dos autores.

${ }^{a}$ Nota: Em negrito, valores estatisticamente significativos a 5\%. (1) Pareamento pelo algoritmo Kernel. 
Tabela 11: Análise de sensibilidade (Rosenbaum Bounds) para frequência escolar e trabalho dos jovens: rural e urbano

\begin{tabular}{l|c|c|c|c}
\hline \multirow{2}{*}{ Situação de Estudo e Trabalho } & \multicolumn{2}{|c|}{ Urbano } & \multicolumn{2}{c}{ Rural } \\
\cline { 2 - 5 } & Q_mh & p_mh & Q_mh & p_mh \\
\hline Trabalha e Não Estuda & 1,549 & 0,061 & 6,938 & 0,000 \\
Trabalha e Estuda & 4,883 & 0,000 & 5,888 & 0,000 \\
Estuda e Não Trabalha & 0,311 & 0,378 & 6,134 & 0,000 \\
Não Estuda e Não Trabalha & 5,982 & 0,000 & 5,867 & 0,000 \\
\hline
\end{tabular}

Fonte: Resultado da pesquisa. Elaboração dos autores.

Tabela 12: Efeito de programas sociais sobre frequência escolar e trabalho dos jovens: estimativas do ATT sobre o viés mínimo e viés corrigido - urbano

\begin{tabular}{|c|c|c|c|}
\hline \multirow[b]{2}{*}{ Situação } & \multirow[b]{2}{*}{ Theta } & \multicolumn{2}{|c|}{ Urbano } \\
\hline & & MB & MB-BC \\
\hline Trabalha e Não Estuda & $\begin{array}{l}0,05 \\
0,25\end{array}$ & $\begin{array}{c}0,006 \\
{[-0,022 ; 0,083]} \\
0,032 \\
{[0,008 ; 0,060]}\end{array}$ & $\begin{array}{c}-0,265 \\
{[-0,772 ; 0,427]} \\
-0,238 \\
{[-0,772 ; 0,410]}\end{array}$ \\
\hline Estuda e Não Trabalha & $\begin{array}{l}0,05 \\
0,25\end{array}$ & $\begin{array}{c}0,04 \\
{[-0,041 ; 0,106]} \\
0,001 \\
{[-0,028 ; 0,041]}\end{array}$ & $\begin{array}{c}0,897 \\
{[0,266 ; 1,501]} \\
0,859 \\
{[0,251 ; 1,479]}\end{array}$ \\
\hline
\end{tabular}

Fonte: Resultado da pesquisa. Elaboração dos autores.

Assim, de acordo com os resultados expostos da tabela, nota-se que o ATT pelo viés corrigido é estatisticamente significativo e positivo em relação aos jovens que "estuda e não trabalha" no meio urbano, dado que no domicílio existe a presença de beneficiários de programas sociais. Desse modo, concluise que, a ajuda financeira cedida às famílias de baixa renda contribui positivamente na acumulação de capital humano dos jovens de famílias beneficiárias.

\section{Considerações Finais}

Este trabalho buscou ampliar o debate na literatura sobre o status dos jovens entre estudar e trabalhar. O diferencial do presente estudo consistiu em analisar a frequência e oferta de trabalho dos jovens, dadas às condições de rendas oriundas de aposentadorias, pensões e programas sociais aplicando diferentes métodos de pareamento e corrigindo o viés relacionado a variáveis omitidas que podem afetar os resultados encontrados.

Uma das principais limitações deste estudo foi a identificação com precisão absoluta do grupo de controle de indivíduos que não recebem aposentadorias e pensões. Já que, para receber aposentadorias, além da idade, outras características são necessárias, como por exemplo: tempo de serviço, tempo 
de contribuição na previdência social, doenças, invalidez e outras variáveis que não são capturadas pelo questionário aplicado na PNAD.

Situação semelhante ocorreu para a identificação dos beneficiários de programas sociais e de seu grupo de controle, uma vez que não existe nas PNADs uma pergunta específica para participação, exceto, nas PNADs com suplementos. A solução desse problema foi considerar como beneficiárias de programas sociais as famílias que declararam na questão de rendas provenientes de programas sociais e outros rendimentos receber a quantia paga pelo Programa Bolsa Família e o Programa de Erradicação do Trabalho Infantil (PETI) nos meses de referência (agosto e setembro de 2014) e que atendessem aos critérios de elegibilidade aos programas, como renda domiciliar per capita e crianças de zero a dezessete anos de idade.

Com base nos resultados apresentados foi possível concluir que, nos domicílios em que pelo menos um indivíduo recebe aposentadoria e/ou pensão, em média, é reduzida a oferta de mão de obra dos jovens de 15 a 21 anos e aumenta sua frequência escolar, quando comparados a jovens que vivem em domicílios com características próximas, na zona urbana. No meio rural, nenhum dos resultados foi estatisticamente significativo quando aplicado o PSM.

Para os jovens que "não estudam e não trabalham", na zona urbana, constatou-se um sinal negativo pelo método do PSM, contudo, foi estatisticamente não significativo. No entanto, após corrigir o viés relacionado a variáveis omitidas pela técnica desenvolvida por Millimet \& Tchernis (2012), os resultados foram estatisticamente significativos e positivos, corroborando os resultados de Reis \& Camargo (2007). Estes afirmam que aposentadorias e pensões aumentam a probabilidade de os jovens estarem em situação de "nem-nem". Ao mesmo tempo reforça os resultados apresentados por Hoffmann (2010), segundo o qual; o comportamento dos jovens que não estudam e não trabalham é menos sensível na presença de indivíduos beneficiários de aposentadorias e pensões.

Nas regressões relacionadas ao impacto de programas sociais, o sinal do coeficiente de variação entre os grupos de tratados e controle para os jovens que "trabalham e não estudam", na zona urbana e, "trabalham e estudam" foi positivo e estatisticamente significativo, tanto no meio rural como urbano. Na categoria "estuda e não trabalha" nenhuma inferência estatística foi observada.

No que diz respeito aos jovens que "não estuda e não trabalha" o impacto de programas sociais foi negativo e significativo, tanto para a amostra na zona urbana, como rural. Os resultados mostraram, portanto, que, nesses domicílios, os jovens, ou estão inseridos no mercado de trabalho, ou estudando.

Ao aplicar o teste de Análise de Sensibilidade, foi observado que variáveis ocultadas do modelo em relação ao meio rural não afetam os resultados encontrados, logo os resultados são robustos. E nas áreas urbanas, de acordo com o teste, haviam variáveis omitidas afetando os resultados nas categorias "trabalha e não estuda" e "estuda e não trabalha", sendo necessário a corre- 
ção pelo viés mínimo e viés corrigido a partir da técnica desenvolvida por Millimet \& Tchernis (2012). Observou-se que o ATT pelo viés corrigido foi estatisticamente significativo e positivo em relação aos jovens que "estuda e não trabalha". Constatando, portanto, que a ajuda financeira cedida as famílias dos jovens de baixa renda é um importante mecanismo na acumulação de capital humano.

Portanto, pelos resultados encontrados, acredita-se que a renda da família é um dos fatores mais importantes para a ampliação de capital humano dos jovens. Políticas públicas de auxílio às famílias e distribuição de renda podem melhorar as condições dos jovens de famílias pobres que necessitam entrar no mercado de trabalho em idade precoce para complementar ou suprir as necessidades financeiras da família.

\section{Referências Bibliográficas}

Araújo, G. S., Ribeiro, R. \& Neder, H. D. (2010), 'Impactos do Programa Bolsa Família sobre o trabalho de crianças e adolescentes residentes na área urbana em 2006', 11(4).

Aroca, P., Brida, J. \& Volo, S. (2014), 'Tourism statistics: correcting data inadequacy using coarsened exact matching', School of Economics and Management at the Free University of Bozen .

Barros, R. P., Carvalho, M. \& Franco, S. (2007a), 'O papel das transferências públicas na queda recente da desigualdade de renda brasileira', Desigualdade de Renda no Brasil: Uma Análise da Queda Recente 2, 41-86.

Barros, R. P., Carvalho, M. \& Franco, S. (2007b), O papel das transferências públicas na queda recente da desigualdade de renda brasileira, in 'Desigualdade de Renda no Brasil: Uma Análise da Queda Recente', Vol. 2, pp. 41-86.

Becker, K. L., Costa, J. S. \& Pavão, A. (2014), 'Determinantes do trabalho infantil no Brasil rural', Rev. de Economia Agrícola 61(1), 49-61.

Becker, S. O. \& Ichino, A. (2002), 'Estimation of average treatment effects based on propensity scores', The Stata Journal 2(4), 358-377.

Blackwell, M., Iacus, S., King, G. \& Porro, G. C. (2009), 'Coarsened exact matching in Stata', The Stata Journal 9(4), 524-546.

Brasil (2014), 'Instituto Brasileiro de Geografia e Estatística - IBGE', Dicionário da Pesquisa por Amostra de Domicílios - PNAD .

Brasil (2016), 'Ministério do Desenvolvimento Agrário', <http://mds.gov.br/>

Cabanas, P., Komatsu, B. K. \& Menezes, F. N. (2014), Crescimento da renda e as escolhas dos jovens entre os estudos e o mercado de trabalho, in ' 42 Encontro Nacional de Economia'.

Cacciamali, M. C., Tatei, F. \& Batista, N. B. (2010), 'Impactos do Programa Bolsa Família federal sobre o trabalho infantil e a frequência escolar', Revista de Economia Contemporânea 14(2), 269-301. 
Caliendo, M. \& Becker, O. S. (2007), 'Sensitivity analysis for average treatment effects', The Stata Journal 7(1), 71-83.

Camarano, A. A. \& Kanso, S. (2012), 'O que estão fazendo os jovens que não estudam, não trabalham e não procuram trabalho?', Nota Técnica: Mercado de Trabalho (53).

Camarano, A. A., Mello, J. L., Pasinato, M. T. \& Kanso, S. (2004), 'Caminhos para a vida adulta: as múltiplas trajetórias dos jovens brasileiros', 12(21), 1150 .

Datta, N. (2015), 'Evaluating impacts of watershed development program on agricultural productivity, Income, and livelihood in Bhalki Watershed of Bardhaman District, West Bengal', World Development 66, 443-456.

Delgado, G. C. \& Cardoso Jr., J. C. (1999), 'O idoso e a previdência rural no Brasil: a experiência recente da universalização'.

Delgado, G. \& Castro, J. A. (2003), 'Financiamento da previdência rural: situação atual e mudanças', IPEA .

Diprete, T. \& Gangl, M. (2004), 'Assessing bias in the estimation of causal effects: Rosenbaum Bounds on matching estimators and instrumental variables estimation with imperfect instruments', 34, 271-310.

Ferreira, B. \& Alves, F. (2009), 'Juventude rural: alguns impasses e sua importância para a agricultura familiar', Juventude e Politicas Sociais no Brasil pp. 245-258.

Ferreira, C. R. \& Souza, S. C. I. (2007), 'As aposentadorias e pensões e a concentração dos rendimentos domiciliares per capita no Brasil e na sua área rural: 1981 a 2003', Revista de Economia e Sociologia Rural 45(4), 985-1011.

Foguel, M. \& Barros, R. P. (2010), 'The effects of conditional cash transfer programmes on adult labour supply: an empirical analysis using a time series-cross-section sample of Brazilian municipalities', Estudos Econômicos 40(2), 259-293.

Gonzaga, G., Corseuil, C., Foguel, M. \& Ribeiro, E. (2012), 'The effects of and apprenticeship program on labor market outcomes of youths in Brazil, in 34 Meeting of the Brazilian Econometric Society'.

Heckman, J. J. (1976), 'The common structure of statistical models of truncation, sample selection and limited dependent variables and a simple estimator for such models', Annals of Economic and Social Measurement 5(4), 475492.

Heckman, J. J. (1979), 'Sample selection bias as a specification error', Econometrica 47(1), 153-161.

Heckman, J. J., Lalonde, R. J. \& Smith, J. A. (1999), 'The economics and econometrics of active labor market programs', Handbook of Labor Economics 3, 1865-2097. 
Hirano, K. \& Imbens, G. W. (2001), 'Estimation of causal effects using propensity score weighting: an application to data on right heart catheterization', Health Services and Outcomes Research Methodology 2(3), 259-278.

Hoffmann, R. (2010), 'Como aposentadorias e pensões afetam a educação e o trabalho de jovens do domicílio', Revista Economia e Sociedade 19(38), 201209.

Iacus, S., King, G. \& Porro, G. (2011), 'Causal inference without balance checking: coarsened exact matching', Political Analysis .

Iacus, S. M. \& King, G. (2009), 'Matching for causal inference without balance checking'.

Lee, W.-S. (2013), 'Propensity score matching and variations on the balancing test', Empirical Economics 44, 44-47.

Millimet, D. L. \& Tchernis, R. (2012), 'Estimation of treatment effects without an exclusion restriction: with an application to the analysis of the school breakfast program', Journal of Applied Econometrics .

Nascimento, A. R. \& Kassouf, A. L. (2014), 'Trabalho infantil: impacto do Programa Bolsa Família', LII Encontro Nacional de Economia, Associação Nacional dos Centros de Pós-Graduação em Economia - ANPEC .

Nascimento, A. R. \& Kassouf, A. L. (2016), 'Trabalho infantil: impacto do Programa Bolsa Família', XLII Encontro Nacional de Economia .

Pedroso, L. G. \& Côrrea, L. F. C. (2014), 'Uma análise do impacto do Programa Bolsa Família na redução do trabalho infantil no Brasil entre 2004 e 2011', Publicatio UEPG: Ciências Humanas, Linguística, Letras e Artes 22(1), 35.

Pedroso, L. G. \& Côrrea, L. F. C. (2015), 'Uma análise do impacto do Programa Bolsa Família na redução do trabalho infantil no Brasil entre 2004 e 2011', Publicatio UEPG: Ciências Humanas, Linguística, Letras e Artes $22(1), 35$.

Reis, M. (2013), 'Transições do desemprego para o emprego entre os jovens', Mercado de Trabalho .

Reis, M. C. \& Camargo, J. M. (2007), 'Impactos de aposentadorias e pensões sobre a educação e a participação dos jovens na força de trabalho', Pesquisa e Planejamento Econômico 37(2).

Rosenbaum, P. R. (2002), 'Observational Studies', New York Springer .

Rosenbaum, P. \& Rubin, D. (1983), 'Assessing sensitivity to an unobserved binary covariate in an observational study with binary outcome', Journal of the Royal Statistical Society pp. 212-218.

Schurer, S., Alspach, M., MaCrae, J. \& Martin, G. L. (2015), 'The medical care costs of mood disorders: a coarsened exact matching approach', IZA Discussion Papers . 
Silva, M. M. C., Costa, L. V. \& Gomes, M. F. M. (2012), 'Entraves ao acesso e à conclusão do ensino médio em áreas rurais e urbanas brasileiras', Revista Economia e Desenvolvimento (1).

Siqueira, L. B. (2015), 'Geração nem-nem e o efeito das aposentadorias e pensões', Tese de Doutorado, Universidade Federal da Paraíba .

Soares, S., Souza, P. H. G. F., Osório, R. G. \& Silveira, F. G. (2010), 'Os impactos do benefício do Programa Bolsa Família sobre a desigualdade e pobreza', pp. 27-529.

Vieira, C. S., Menezes-Filho, N. \& Komatsu, B. K. (2015), 'Como as mudanças no trabalho e renda dos pais afetam as escolhas entre estudo e trabalho dos jovens?', Encontro Nacional de Economia .

\section{Apêndice A}

Tabela A.1: Estimativa do modelo logit - tratamento (aposentadorias e pensões) - Brasil - urbano e rural

\begin{tabular}{|c|c|c|c|c|}
\hline \multirow{2}{*}{ Variáveis } & \multicolumn{2}{|c|}{ Urbano } & \multicolumn{2}{|c|}{ Rural } \\
\hline & Coef. & EP & Coef. & EP \\
\hline Mulheres maiores 55 & 1,148 & 0,046 & 2,139 & 0,133 \\
\hline Homens maiores 60 & 1,066 & 0,059 & 2,460 & 0,159 \\
\hline Crianças menores 5 & $-0,333$ & 0,048 & $-0,124$ & 0,188 \\
\hline Crianças 6 a 10 & $-0,415$ & 0,050 & $-0,037$ & 0,188 \\
\hline Crianças 11 a 14 & $-0,387$ & 0,047 & $-0,151$ & 0,186 \\
\hline Adolescentes 15 a 21 & $-0,046$ & 0,028 & 0,022 & 0,080 \\
\hline Compposição familiar & 0,425 & 0,037 & 0,091 & 0,171 \\
\hline Idade chefe & 0,038 & 0,002 & 0,037 & 0,005 \\
\hline Chefe branco & 0,246 & 0,033 & 0,278 & 0,105 \\
\hline Chefe idoso & 0,298 & 0,071 & $-0,186$ & 0,248 \\
\hline Viúvo & 1,952 & 0,049 & 2,640 & 0,148 \\
\hline Chefe agricultor & $-0,252$ & 0,059 & $-0,281$ & 0,098 \\
\hline Sem instrução & $-0,476$ & 0,044 & $-0,118$ & 0,171 \\
\hline Educação 1 a 3 & $-0,556$ & 0,046 & $-0,119$ & 0,172 \\
\hline Educação 4 a 7 & $-0,480$ & 0,036 & $-0,081$ & 0,167 \\
\hline Educação 8 a 10 & $-0,486$ & 0,036 & $-0,117$ & 0,170 \\
\hline Educação maior 11 & $-0,444$ & 0,036 & $-0,002$ & 0,174 \\
\hline Trabalhador principal & $-0,001$ & 0,000 & $-0,001$ & 0,000 \\
\hline Constante & $-3,023$ & 0,081 & $-3,596$ & 0,247 \\
\hline Pseudo R2 & & 0,2659 & & 0,3863 \\
\hline Suporte Comum & {$[0,00269$} & 9162108] & {$[0,00012$} & $9850468]$ \\
\hline
\end{tabular}

Fonte: Resultado da pesquisa. Elaboração dos autores. 
Tabela A.2: Qualidade do balanço antes e depois do matching (aposentadorias e pensões) - Brasil - urbano e rural

\begin{tabular}{l|r|r|r|r|r|r|r|r}
\hline \multirow{2}{*}{ Pareamento } & \multicolumn{4}{|c|}{ Urbano } & \multicolumn{3}{c}{ Rural } \\
\cline { 2 - 9 } & Pseudo R2 & LR Chi2 & $\begin{array}{c}\text { Viés } \\
\text { Médio }\end{array}$ & $\begin{array}{c}\text { Viés } \\
\text { Mediano }\end{array}$ & Pseudo R2 & LR Chi2 & $\begin{array}{c}\text { Viés } \\
\text { Médio }\end{array}$ & $\begin{array}{c}\text { Viés } \\
\text { Mediano }\end{array}$ \\
\hline Antes do Pareamento & 0,265 & 10579,04 & 28,6 & 11,0 & 0,381 & 2354,00 & 32,6 & 14,4 \\
Matching Nearest Neighbor & 0,113 & 2820,65 & 19,0 & 8,3 & 0,211 & 759,71 & 25,8 & 15,7 \\
Matching Radius & 0,007 & 164,00 & 3,3 & 3,4 & 0,016 & 57,91 & 5,5 & 4,1 \\
Matching Kermel & 0,007 & 164,04 & 3,3 & 3,4 & 0,016 & 54,85 & 5,5 & 3,8 \\
\hline
\end{tabular}

Fonte: Resultado da pesquisa. Elaboração dos autores. 
Tabela A.3: Estimativa do modelo logit - tratamento (programas sociais) - Brasil - urbano e rural

\begin{tabular}{|c|c|c|c|c|}
\hline \multirow{2}{*}{ Variáveis } & \multicolumn{2}{|c|}{ Urbano } & \multicolumn{2}{|c|}{ Rural } \\
\hline & Coef. & EP & Coef. & EP \\
\hline Sexo chefe & $-0,213$ & 0,045 & $0,130^{* * * *}$ & 0,096 \\
\hline Idade chefe & 0,008 & 0,002 & $0,001^{* * *}$ & 0,004 \\
\hline Cor chefe & $-0,140$ & 0,049 & $-0,186^{* * *}$ & 0,097 \\
\hline Chefe sem instruçao & 1,083 & 0,159 & $-0,398^{* * *}$ & 0,388 \\
\hline Educação 1 a 3 & 1,064 & 0,155 & $-0,557^{* * *}$ & 0,387 \\
\hline Educação 4 a 7 & 0,885 & 0,148 & $-0,676^{* * *}$ & 0,386 \\
\hline Educação 8 a 10 & 0,538 & 0,151 & $-0,506^{* * *}$ & 0,397 \\
\hline Educação mais de 11 & 0,396 & 0,150 & $-0,879^{* *}$ & 0,404 \\
\hline Dummy_cc & $-0,415^{* * *}$ & 0,063 & $-0,778^{* * *}$ & 0,138 \\
\hline Dummy_sc & $0,038^{* * *}$ & 0,065 & $0,040^{* * * *}$ & 0,107 \\
\hline Dummy_ds & $-0,116$ & 0,086 & $-0,277^{* * *}$ & 0,325 \\
\hline Ocupação cônjuge & 0,250 & 0,088 & $0,167^{* * * *}$ & 0,313 \\
\hline Crianças menores 5 & 0,328 & 0,037 & 0,942 & 0,080 \\
\hline Crianças 6 a 10 & 0,345 & 0,042 & 0,832 & 0,112 \\
\hline Crianças 11 a 15 & 0,360 & 0,030 & 1,098 & 0,064 \\
\hline Adolescentes 16 e 17 & 0,416 & 0,038 & 1,208 & 0,074 \\
\hline Casado & $0,169^{* *}$ & 0,078 & $0,196^{* * *}$ & 0,143 \\
\hline Domicílio permanente & $1,592^{* * *}$ & 1,263 & $-0,754^{* * *}$ & 0,941 \\
\hline Cobertura adequada & $-0,013^{* * *}$ & 0,131 & $0,275^{* * *}$ & 0,178 \\
\hline Água canalizada & 0,127 * & 0,072 & $0,201 * *$ & 0,097 \\
\hline Saneamento adequado & $-0,523$ & 0,044 & $-0,016^{* * *}$ & 0,245 \\
\hline Lixo adequado & $-0,036^{* * *}$ & 0,193 & $-0,339$ & 0,102 \\
\hline Eletricidade & $-1,359^{* * *}$ & 1,116 & $0,454^{* *}$ & 0,214 \\
\hline Constante & $-1,629^{* *}$ & 0,574 & $-0,601^{* * *}$ & 1,011 \\
\hline Pseudo R2 & & 0,065 & & 0,187 \\
\hline Suporte Comum & {$[0,13681992 ;$} & 89754478] & {$[0,20698141$} & ,99929646] \\
\hline
\end{tabular}


Tabela A.4: Qualidade do balanço antes e depois do matching (programas sociais) - Brasil - urbano e rural

\begin{tabular}{l|c|c|c|c|c|c|c|c}
\hline \multirow{2}{*}{\multicolumn{1}{c}{ Pareamento }} & \multicolumn{4}{c|}{ Urbano } & \multicolumn{3}{c}{ Rural } \\
\cline { 2 - 8 } & Pseudo R2 & LR Chi2 & $\begin{array}{c}\text { Viés } \\
\text { Médio }\end{array}$ & $\begin{array}{c}\text { Viés } \\
\text { Mediano }\end{array}$ & Pseudo R2 & LR Chi2 & $\begin{array}{c}\text { Viés } \\
\text { Médio }\end{array}$ & $\begin{array}{c}\text { Viés } \\
\text { Mediano }\end{array}$ \\
\hline Antes do Pareamento & 0,065 & 935,32 & 11,2 & 11,3 & 0,180 & 848,09 & 13,7 & 7,2 \\
Matching Nearest Neighbor & 0,045 & 625,02 & 8,7 & 9,3 & 0,047 & 174,60 & 5,5 & 3,8 \\
Matching Radius & 0,001 & 16,70 & 1,0 & 1,0 & 0,016 & 100,77 & 4,7 & 3,6 \\
Matching Kermel & 0,001 & 16,81 & 1,0 & 0,8 & 0,016 & 101,13 & 4,8 & 4,0 \\
\hline \multicolumn{2}{l}{ Fonte: Resultado da pesquisa. Elaboração dos autores. }
\end{tabular}


